\title{
Modification of LEACH Protocol for Improving the Stability Period and Lifetime of WSN
}

\author{
by \\ Vermareddy Sandeep Reddy \\ A research study submitted in partial fulfillment of the requirements for the \\ degree of Master of Engineering in \\ Information and Communications Technologies
}
Examination Committee: $\quad$ Dr. Teerapat Sanguankotchakorn (Chairperson) Dr. Attaphongse Taparugssangorn Prof. Nitin Kumar Tripathi

\begin{abstract}
Nationality: Indian
Previous Degree: Bachelor of Technology in Electronics and

Communications Engineering

Jawaharlal Nehru Technological University

Hyderabad, Telangana, India
\end{abstract}

Scholarship Donor: $\quad$ AIT Fellowship

Asian Institute of Technology

School of Engineering and Technology

Thailand

May 2019 


\section{ACKNOWLEDGEMENTS}

I would like to express my profound gratitude to my research advisor Dr. Teerapat Sanguankotchakorn, for steering me in the right direction, throughout the completion of my research study. His understanding is unsurpassed and I am greatly indebted to him.

I also would like to express my gratitude to my committee members Dr.Attaphongse Taparugssangorn and Professor Nitin Kumar Tripathi, for their invaluable comments and suggestions, towards the progress of my research. I am very happy and thankful to them, in every aspect, that guided me towards the completion of my research.

I am very happy and thankful to the staff of AIT-TC department, Ms Premma Rao, Mr. Rajesh Dehury and Mr.Jarook, for providing me the necessary things and equipment on happening hours and non-happening hours, throughout my research period. I thank all my friends from the department of TC \& ICT, as well as people of AIT, for providing the love and support for the completion of my research.

Last, but not the least, I would like to thank my parents and brother, for their constant encouragement, love and support, every single day.

Best regards, V.Sandeep Reddy. 


\begin{abstract}
As we are moving towards smart homes and smart cities, the need for wireless sensors are increasing continuously. Most of the sensors are powered with batteries, which have limited amount of power. So, in a wireless sensor network, the main motive is to minimize the energy consumption and increase the lifetime of the network. Communication between the sensors and from sensors to sink is an energy consuming process. Here comes, the LEACH protocol, with the concept of clustering, that makes the network energy efficient and gives longer lifetime to the network. This LEACH protocol has many drawbacks. One among them is the uneven distribution of $\mathrm{CHs}$ in the network, in several rounds. This leads to higher consumption of energy by sensor nodes, which in turn reduces the stability period and also the overall lifetime of the network. This problem is solved to majority extent in this research by concept of dividing the sensor field into sub-regions and choosing cluster head from each sub-region. This modification reduces the uneven distribution of $\mathrm{CHs}$ to maximum extent. Modified protocol is simulated in MATLAB and its results show that, the stability period as well as overall lifetime is improved than existing basic LEACH protocol.
\end{abstract}




\section{TABLE OF CONTENTS}

CHAPTER TITLE

PAGE

Title Page

Acknowledgements

Abstract

Table of Contents

List of Tables

List of Figures

List of Abbreviations

List of Symbols and Notations

iii

iv

vi

vii

ix

Introduction

1.1 Background

1.2 Problem statement

1.3 Objectives

1.4 Scope and Limitations

1.5 Organization of the report

Literature Review

2.1 Terminology of wireless sensor network

2.2 LEACH (Low Energy Adaptive Clustering Hierarchy)

2.2.1 Setup Phase

2.2.2 Steady State Phase

2.3 Flow Chart of Setup Phase in LEACH

2.4 Dynamic Clustering in LEACH

2.5 LEACH Operation timeline

2.5.1 Setup Phase Operation

2.5.2 Steady State Phase Operation

2.6 First Order Radio Energy Model 10

2.7 Advantages of LEACH 11

2.8 Disadvantages and Limitations of LEACH 11

2.9 Lifetime of a Sensor Node $\quad 12$

2.10 Related Research Work 12

$3 \quad$ Methodology 14

$\begin{array}{lll}3.1 & \text { Contribution } & 14\end{array}$

3.2 Proposed Approach 14

3.3 Cluster Head Selection Modification 14

3.4 Methodology for the Proposed Approach 15

3.5 Pseudo Code for the Proposed Approach 17

3.6 Simulation Parameters (i) 19

3.7 Simulation Parameters (ii) 20

$\begin{array}{ll}3.7 & \text { Simulation Environment } 20\end{array}$

$4 \quad$ Simulation Results and Discussions $\quad 21$

$\begin{array}{lll}4.1 & \text { Simulation Environment } & 21\end{array}$

4.2 Performance Evaluation Metrics 21 
4.3 Simulation Results 21

4.4 Deployment Scenario A 22

4.5 Deployment Scenario B 23

4.6 Performance Graphs 24

4.7 Analysis of Simulation Results 38

$5 \quad$ Conclusion and Future Recommendations 39

5.1 Conclusion 39

5.2 Future Recommendations 39

$6 \quad$ References 40

$\begin{array}{lll}7 & \text { Appendixes } & 42\end{array}$ 


\section{LIST OF TABLES}

TABLE TITLE

PAGE

$\begin{array}{lll}3.1 & \text { Simulation parameters (i) } & 19\end{array}$

$3.2 \quad$ Simulation parameters (ii) 20

4.1 Network lifetime of LEACH and modified LEACH for 50 nodes 25

4.2 Network lifetime of LEACH and modified LEACH for 50 nodes 27

4.3 Network lifetime of LEACH and modified LEACH for 100 nodes 29 in $50 \mathrm{~m} \times 50 \mathrm{~m}$ network size, initial energy $=1 \mathrm{~J} /$ node

$4.4 \quad$ Network lifetime of LEACH and modified LEACH for 100 nodes in $100 \mathrm{~m} \times 100 \mathrm{~m}$ network size, initial energy $=1 \mathrm{~J} /$ node

4.5 Network lifetime of LEACH and modified LEACH for 150 nodes in $50 \mathrm{~m} \times 50 \mathrm{~m}$ network size, initial energy $=1 \mathrm{~J} /$ node

4.6 Network lifetime of LEACH and modified LEACH for 150 nodes in $100 \mathrm{~m} \times 100 \mathrm{~m}$ network size, initial energy $=1 \mathrm{~J} /$ node

4.7 Network lifetime of ILEACH (Zhao et al., 2012) and modified LEACH for 100 nodes in $100 \mathrm{~m} \times 100 \mathrm{~m}$ network size, initial energy $=0.03 \mathrm{~J} /$ node 


\section{LIST OF FIGURES}

FIGURE TITLE

PAGE

$2.1 \quad$ WSN consisting of $\mathrm{CH}, \mathrm{NON}-\mathrm{CH}$ and Base station 4

$2.2 \quad$ Flow chart of the setup phase in LEACH 6

$2.3 \quad$ Dynamic clustering in LEACH, in two different rounds 7

$2.4 \quad$ LEACH operation timeline 8

$\begin{array}{llr}2.5 & \text { Radio Energy Model } & 10\end{array}$

3.1 Methodology of the proposed modified LEACH 16

$4.1 \quad$ Deployment scenario for $50 \times 50 \mathrm{~m}^{2}$ size network 18

$4.2 \quad$ Deployment scenario for $100 \times 100 \mathrm{~m}^{2}$ size network 19

$4.3 \quad$ Performance results of LEACH and modified LEACH for $50 \quad 24$

nodes in $50 \mathrm{~m} \times 50 \mathrm{~m}$ network size, with initial energy $=1 \mathrm{~J} /$ node

(i)

4.4 Performance results of LEACH and modified LEACH for 50

nodes in $100 \mathrm{~m} \times 100 \mathrm{~m}$ network size, with initial energy $=1 \mathrm{~J} /$ node (ii)

4.5 Performance results of LEACH and modified LEACH for 50 nodes in $100 \mathrm{~m} \times 100 \mathrm{~m}$ network size, with initial energy $=1 \mathrm{~J} /$ node (i)

4.6 Performance results of LEACH and modified LEACH for 50 nodes in $100 \mathrm{~m} \times 100 \mathrm{~m}$ network size, with initial energy $=1 \mathrm{~J} /$ node (ii)

4.7 Performance results of LEACH and modified LEACH for 100 nodes in $50 \mathrm{~m} \times 50 \mathrm{~m}$ network size, with initial energy $=1 \mathrm{~J} /$ node (i)

4.8 Performance results of LEACH and modified LEACH for 100 nodes in $50 \mathrm{~m} \times 50 \mathrm{~m}$ network size, with initial energy $=1 \mathrm{~J} /$ node (ii)

4.9 Performance results of LEACH and modified LEACH for 100 nodes in $100 \mathrm{~m} \times 100 \mathrm{~m}$ network size, with initial energy $=1 \mathrm{~J} /$ node (i)

4.10 Performance results of LEACH and modified LEACH for 100 nodes in $100 \mathrm{~m} \times 100 \mathrm{~m}$ network size, with initial energy $=1 \mathrm{~J} /$ node (ii)

4.11 Performance results of LEACH and modified LEACH for 150 nodes in $50 \mathrm{~m} \times 50 \mathrm{~m}$ network size, with initial energy $=1 \mathrm{~J} /$ node (i)

4.12 Performance results of LEACH and modified LEACH for 150 nodes in $50 \mathrm{~m} \times 50 \mathrm{~m}$ network size, with initial energy $=1 \mathrm{~J} /$ node (ii)

4.13 Performance results of LEACH and modified LEACH for 150 nodes in $100 \mathrm{~m} \times 100 \mathrm{~m}$ network size, with initial energy $=1 \mathrm{~J} /$ node (i)

4.14 Performance results of LEACH and modified LEACH for 150 nodes in $100 \mathrm{~m} \times 100 \mathrm{~m}$ network size, with initial energy $=1 \mathrm{~J} /$ node (ii) 
4.16 Performance results of ILEACH (Zhao et al., 2012) and modified LEACH for 100 nodes in $100 \mathrm{~m} \times 100 \mathrm{~m}$ network size, with initial energy $=0.03 \mathrm{~J} /$ node (ii) 


\section{LIST OF ABBREVIATIONS}

WSN

BS

$\mathrm{CH}$

$\mathrm{CM}$

LEACH

TDMA

FND

LND

HNA

$\mathrm{NON}-\mathrm{CH}$
Wireless Sensor Networks

Base Station

Cluster Head

Cluster nodes other than cluster head

Low Energy Adaptive Clustering Protocol

Time Division Multiple Access

First Node Death

Last Node Death

Half of the Nodes Alive

Sensor node which is not a cluster head in that round 


\section{LIST OF SYMBOLS AND NOTATIONS}

$\mathrm{p}$

$\mathrm{G}$

$t_{a d v-C H}$

$E_{T X}$

$\mathrm{r}$

$E_{D A}$

$E_{\text {elec }}$

$E_{a m p}$
Percentage of choosing $\mathrm{CHs}$

Set of cluster nodes that have not been $\mathrm{CHs}$ in the last $1 / \mathrm{p}$ rounds

Cluster head advertisement sending time

Required energy utilization for packet transmission

Number of the current round in the LEACH operation

Energy for the data aggregation

Electronic energy in the radio model

Amplifier energy in the radio model 


\section{CHAPTER 1 \\ INTRODUCTION}

\subsection{Background}

WSN consists of many hundreds of little sensors which are having potential to communicate among them, with constrained amount of energy. Various environmental effects like temperature, pressure, speed etc. can be sensed by deploying these motes. BS or sink is nothing but a sensor node which has interest in collecting the sensed information from nodes, that represents the clusters in the WSN.

The compatibility of WSN and the continuous technology enhancements has led to their use in various applications which include survival monitoring, intelligent buildings, military applications, traffic control, object tracking etc.

However, WSNs suffers from many important limitations such as limited energy which is not rechargeable and security that has to be addressed for all the sensors. Energy efficiency is major issue in these network. In addition to this, consumption of energy of sensors system, also depends on requirements for application for which it is being used. Most of the times WSNs are deployed in environments where, manually a person will not be able to able to change or get the power source of sensors recharged.

Key role in WSN are played by batteries, since they are the indicators of the lifetime of system. Most of the energy in wireless networks is used up in sending the packets. This is how the need for greater protocols having higher efficiency has come into demand. Many types of approaches are started to improve this, in the field of research. (Elshrkawey et al., 2018)

The $\mathrm{CH}$ will take care of minimizing the repeated sensed information and then apply techniques of aggregation that reduces the size of sensed information and transmits it to sink.

LEACH (Low Energy Adaptive Clustering Hierarchy) protocol is well-known protocol that is being implemented in real world applications consisting of micro-sensors network. (Heinzelman et al., 2002)

It combines both the concepts of energy efficient cluster based routing as well as media access, together. The prime motive, at the back of this protocol lies in minimizing the energy consumed in the sensors to the maximum extent, for improving the system lifespan. In the setup phase, the formation of the cluster takes place, following a threshold. The $\mathrm{CHs}$ will be selected at the beginning of each round. Each of the sensor node, will generate a number between $[0,1]$. If the number generated is lesser to threshold, then that sensor will be selected as $\mathrm{CH}$. This sensor will be the $\mathrm{CH}$ for that round. (Heinzelman et al., 2002) 


\subsection{Problem Statement}

Despite the fact that, LEACH protocol conserves the energy in nodes. Some of the problems still exist, in this factor too.

The problem is the non-uniform distribution of CHs in WSN. LEACH won't give a guarantee, of the distribution of $\mathrm{CHs}$ throughout the network region, in every round. The distribution of $\mathrm{CHs}$ which in most of the rounds, when located in only one region makes, the rest of the regions empty. Those sensor nodes that are in the rest of the regions, does not have any cluster head in their proximity.

This makes, the sensor nodes to join the $\mathrm{CHs}$, that are farther from their regions, which in turn causes, high loss of energy to send the sensed information to their respective CHs.

This is one of the major issues which are responsible for higher consumption of energy, which by obvious will lead to reduced lifetime of wireless sensor network.

\subsection{Objectives}

a) To study the working process of LEACH protocol

b) To modify the cluster head selection mechanism based on clustering approach, to the LEACH algorithm.

c) To study the performance characteristics of the improved protocol by simulating the modified algorithm based on stability period parameters and network lifetime.

d) To analyze the effectiveness of the proposed approach by comparing its results with the results of LEACH protocol and evaluating it.

\subsection{Scope and Limitations}

Scope of this research includes to analyze and evaluate the effectiveness of the modified LEACH algorithm based on distributing the CHs uniformly, on the entire network region. Analyzing the working process of LEACH protocol and some of its derivatives and understanding the way they function, will be done in this research. The resulted approach is simulated and outputs will be compared with simulation results of LEACH protocol on stability period parameters and lifetime of the network.

The modified approach's simulated outputs will be compared only with the outputs of the parent LEACH protocol but not with all of its derivatives. This is one of the limitations of the research. 


\subsection{Organization of the Report}

Chapter 1: Gives an overview of the WSN and its problems followed by problem statement and limitations of the research.

Chapter 2: This chapter provides detailed information about the mentioned protocol along with its drawbacks and some summarized literature work.

Chapter 3: Gives detailed methodology for the proposed approach along with the simulation parameters, that were used.

Chapter 4: Provides all the simulation results and analysis on them

Chapter 5: Gives a conclusion of my research study and few future recommendations.

References

Appendix 


\section{CHAPTER 2 \\ LITERATURE REVIEW}

\subsection{Terminology of wireless sensor network}

Base station (BS): Base station or sink is a node that is interested in collecting the transmitted data from a group of sensor nodes.

Clusters: Group of nodes

Cluster Head (CH): A node which represents the cluster and is bound to transmitting the data that is sensed by all of its sensor nodes to the base station.

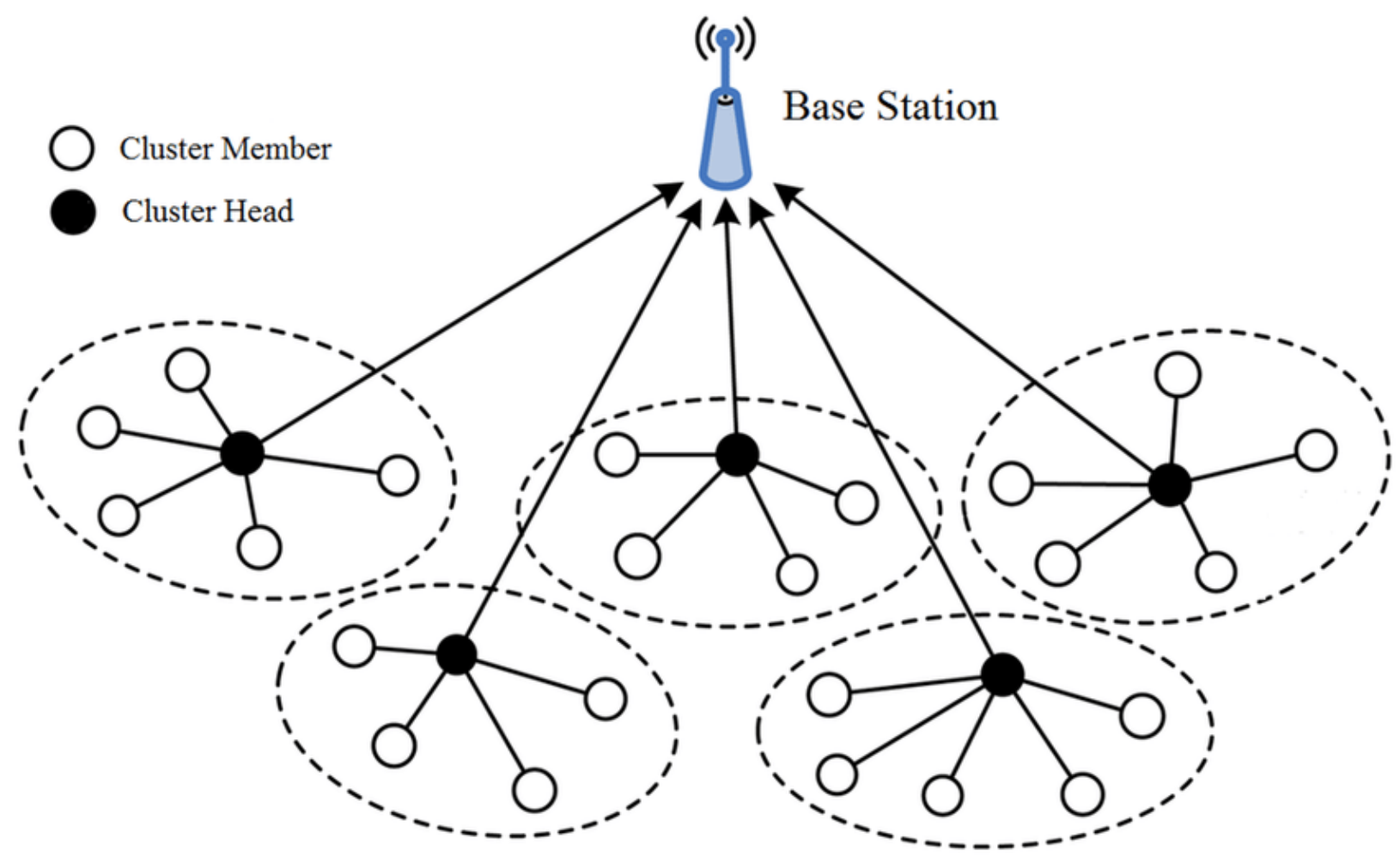

Figure 2.1 WSN consisting of $\mathrm{CH}$, NON-CH and Base station

(Gui et al., 2016)

Network Lifetime: The time period from the starting of the network operation to the death of last node in the network. (Yousaf et al., 2016)

Stability Period: The time period from the starting of the network operation to the first node death. (Yousaf et al., 2016)

Instability Period: The time period between the first node death to the last node death in the network. (Batra \& Kant, 2016). 


\subsection{LEACH (Low Energy Adaptive Clustering Hierarchy)}

LEACH protocol is a well-known routing protocol that is used in the real-world applications of micro-sensors network. The prime motive, at the back of this protocol lies in minimizing the energy consumed in the sensors to the maximum extent, for improving the system lifespan (Heinzelman et al., 2002)

LEACH protocol consists of two phases. First one is setup phase and the other phase is steady state phase. It operates follows these two phases in each round.

In the network, the operation is split into rounds. Each round will start with setup phase and will end with steady state phase. This is a recurring process, till last node death in WSN.

$$
T(n)=\left\{\begin{array}{lr}
\frac{p}{1-p *\left(\operatorname{rmod} \frac{1}{p}\right)} & \text { if } n \in G \\
0 & \text { elsewhere }
\end{array}\right.
$$

where:

p: probability of choosing $\mathrm{CH}$ in each round

$\mathrm{r}$ : is the current round.

$\mathrm{G}$ : is the set of motes that haven't been $\mathrm{CHs}$ in the previous $1 / \mathrm{p}$ rounds

\subsubsection{Setup Phase}

This phase is for the process of selecting the CHs and for the formation of the clusters. Cluster head selection process will be done by the threshold algorithm given in equation 2.1.

- Each node will generate a random number between 0 and 1 .

- This random number will be compared with the threshold value obtained from the equation (2.1) $\mathrm{T}(\mathrm{n})$.

- If this number is lesser to threshold $\mathrm{T}(\mathrm{n})$, then that sensor will get to be $\mathrm{CH}$ for that round.

- If condition satisfied by more than one node in the network, then a random node will be selected as $\mathrm{CHs}$.

- The number of CHs in each round, is controlled or limited by the probability of CHs. This is predetermined in the starting of the operation of the system.

- After the selection of CHs, sensor nodes other than $\mathrm{CHs}$ in that round, will form a cluster by choosing the cluster head sensor node having least distance to them

- The cluster heads allot TDMA schedule to their respective cluster members, to send their sensed data.

- This completes the formation of clusters in that round, and it indicates the end of setup phase and beginning of steady state phase for that round. 


\subsubsection{Steady state phase:}

This phase is for the process of transmitting the packets. These packets are nothing but sensed information sensors and sending it their respective CHs. This phase is generally broken into frames. Each frame consists of time slot given to cluster head members by the cluster head, to send their sensed data in that round.

The process of data transmission takes place using TDMA scheduling. Once the process of intra-cluster communication is completed, then the $\mathrm{CHs}$ transmit the received data as well as sensed data to the base station or sink.

This completes the end of steady state phase and completion of one round. The next round starts with the same process, setup phase again followed by steady state phase. This process goes on until the death of last node in the network. (Heinzelman et al., 2002)

\subsection{Flow Chart of Setup Phase in LEACH}

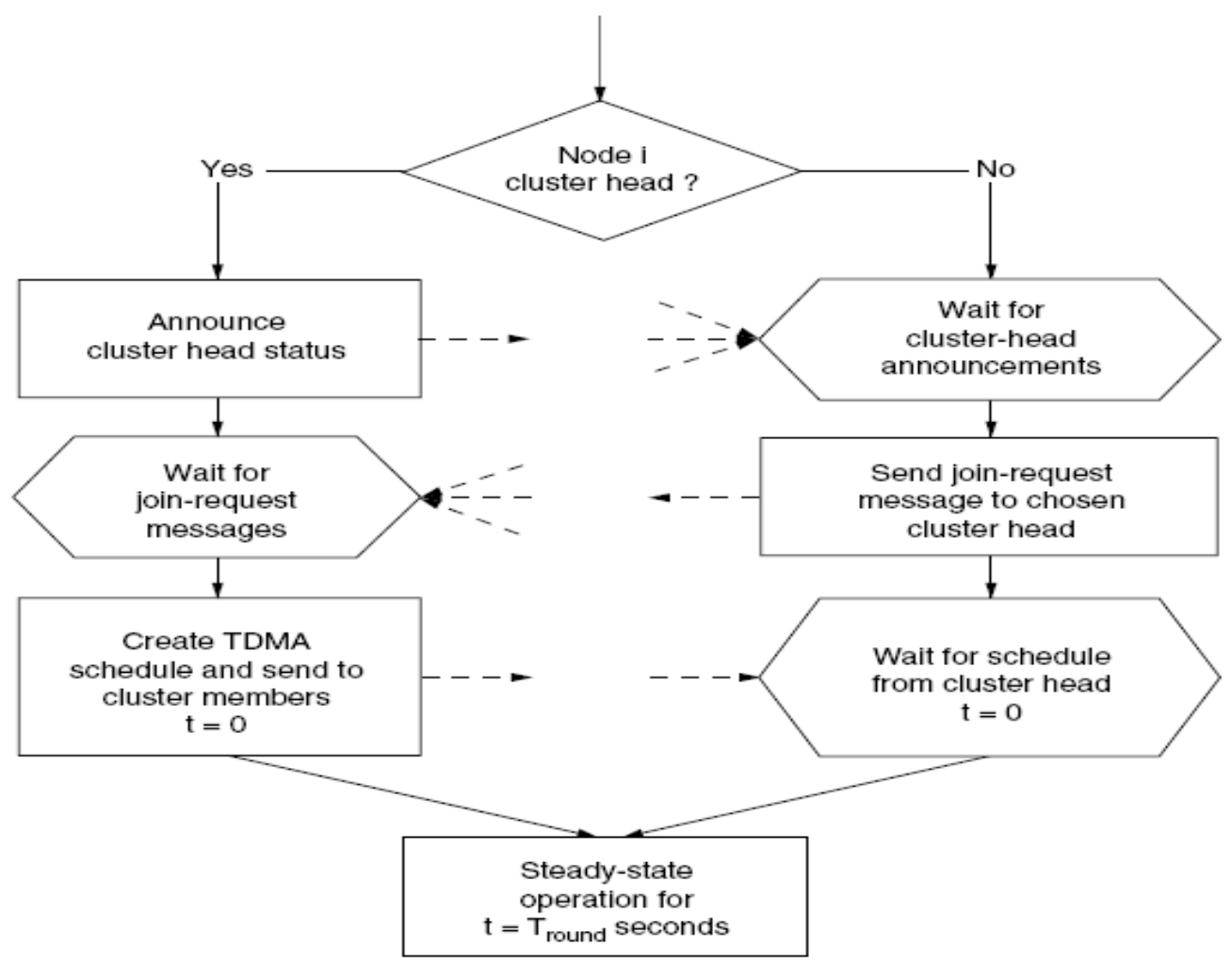

Figure 2.2: Setup phase in LEACH

(Heinzelman, Chandrakasan, \& Balakrishnan, 2002) 


\subsection{Dynamic Clustering in LEACH}

LEACH is a self-adaptive, self-organizing protocol, since the formation of clusters takes place dynamically for each round, on their own, by following the threshold function, limited by the probability which is predetermined at the beginning of the network operation. (Heinzelman et al., 2002)
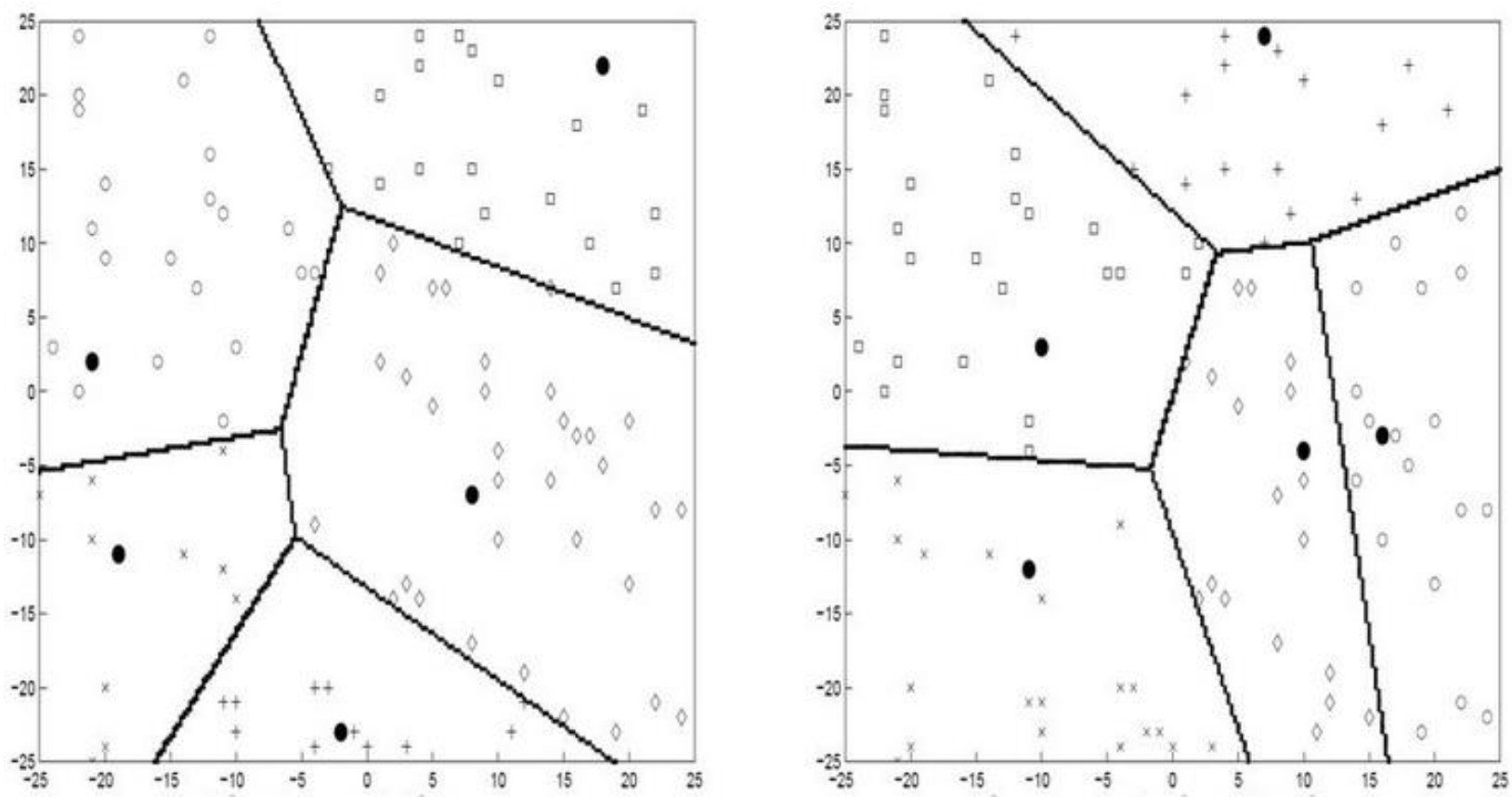

Figure 2.3 Dynamic clustering in LEACH, in two different rounds. (Heinzelman, Chandrakasan, \& Balakrishnan, 2002)

In the above figure, all nodes of same symbol belong to one cluster and the black nodes indicates $\mathrm{CHs}$ of that cluster, in that round. The two figures indicate, dynamic clustering of LEACH protocol, in two different rounds.

\subsubsection{LEACH Operation Timeline}

\subsubsection{Setup Phase Operation}

In the process of being a $\mathrm{CH}$, once the sensors have chosen themselves as $\mathrm{CHs}$, using threshold function, they have to leave message, to remaining sensor nodes in the system, in a way that, they are $\mathrm{CHs}$ in that round.

For this process, each $\mathrm{CH}$ node, announces advertisement message (ADV). This message is nothing but a message, that consists of identity of the node which has a unique number in it and header, that recognizes this as announcement message. This will be done using a protocol named CSMA MAC (Heinzelman et al., 2002)

Then, each non- $\mathrm{CH}$, sensor chooses its group for that round by choosing $\mathrm{CH}$, which needs, least energy to communicate with, which is based on RSSI announcement. This is for every $\mathrm{CH}$. 
Here, considering equal proportional generation, then the $\mathrm{CH}$ advertisement heard with strongest RSSI will be the one $\mathrm{CH}$ that needs least transmission energy to get connected with.

Typically, that would be the nearest $\mathrm{CH}$, to the member node, until and unless, there is an obstacle, obstructing the communication. If there is a tie, in this situation, then a random $\mathrm{CH}$ will be selected.

The non-cluster head members, will identify, their respective clusters. Then, they have to intimate their respective $\mathrm{CHs}$, in a way that, they would like to be part of that cluster, for that round. In the process of this, every normal sensor node, have to transmit a request of joining. This message is (Join- REQ), which has to be transmitted to their respective CHs. This will be done using protocol named CSMA MAC. (Heinzelman et al., 2002)

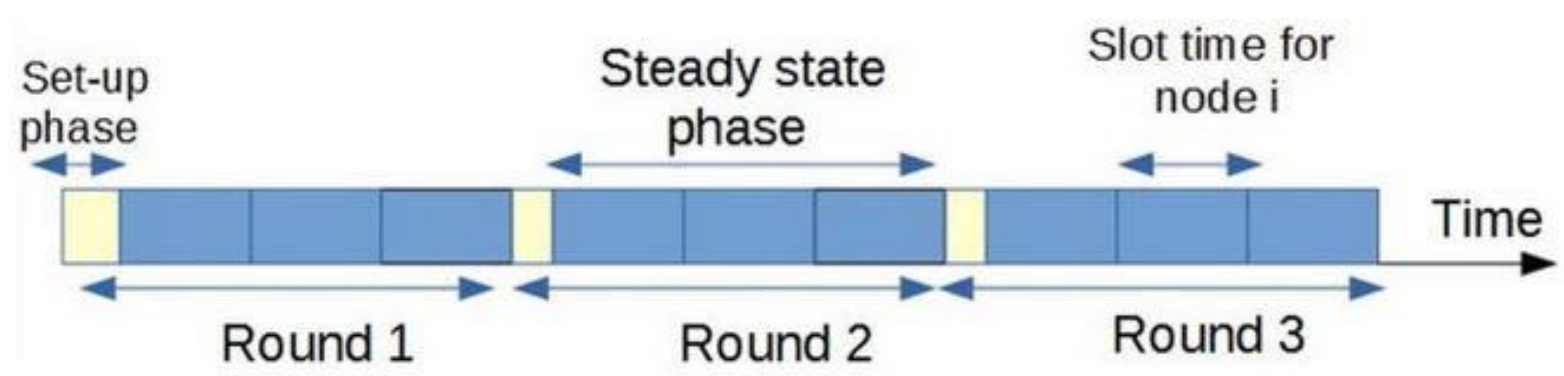

Figure 2.4: LEACH operation timeline (Elshrkawey, Elsmere, \& Wahed, 2018)

This will also be in the form of short message. This message has information of node's unique identification number (ID). It also has cluster head's unique identification number (ID).

$\mathrm{CH}$ in $\mathrm{LEACH}$, acts as coordination centers to correspond transmission of information in the clusters, which they represent. TDMA schedule will be established by the CHs. Then they transmit to all its members in their respective clusters.

This gives an evidence that, there are hardly any collisions between the packets of data. This approach of scheduling also allows the transmitters and receivers of each cluster member node, can put their radio off, every time, except in the slot of theirs to send data, thereby it minimizes the energy consumption by individual sensor nodes.

When all the members of the cluster receive the slots sent by their respective $\mathrm{CHs}$, it indicates the completion of first phase part and the operation of second phase part, begins. 


\subsubsection{Steady State Phase Operation}

The operation of this phase is divided into number of frames. Sensors transmit their packets of sensed information to cluster head, with a max of 1 frame at the allotted transmission time for them. (Heinzelman et al., 2002)

The collected data of the sensor, sent in the time slot allotted to them. The duration of it is same. Then duration of transmitting the frame of packet of sensed information, will depend upon, total count of number of sensors belonging to that cluster.

As an assumption, the consideration is, total of the sensors are synchronized in terms of time. They all begin the first phase part at equivalent point of time.

In order to reduce the dissipation of energy, every cluster member other than the $\mathrm{CH}$, uses its mechanism of controlling of power to configure required transmit power. This depends upon strength of received cluster head announcement. Also, the radio component of every non- $\mathrm{CH}$ will be put to in off mode, till it's given transmitting schedule.

Using TDMA schedule to allocate the time slots, is a productive use of bandwidth, since the protocol is optimized and designed in a way, that when every node in the cluster, have data to transmit it to the $\mathrm{CH}$.

In order to collect the packets of information from non- $\mathrm{CH}$ sensors, by the $\mathrm{CH}$, in its cluster, it must be awake in its steady state phase. As soon as, the packets of information are collected by the $\mathrm{CH}$, techniques of aggregation of data is performed. This is done to improve the beam formed signal and minimize uncorrelated noise, between the signals.

As an assumption, it is considered perfect correlation, by which a single signal can be represented by the combination of these individual signals.

The combined resultant signal, is sent from cluster heads to sink. If base station is located at a longer distance from the network, if there are large data messages, then it can be identified as high energy transmission.

Using CSMA and fixed spreading code, packets of information can be transmitted to $\mathrm{BS}$ by all the $\mathrm{CHs}$ which are present on network. If $\mathrm{CH}$ is having packets of information, that should be sent to sink, it has to check by sensing channel. This is to be done in order to verify, if some other one, is sending to BS, using the code of spreading by sink. If it is so, then the $\mathrm{CH}$, has wait for the packets of information to be transmitted. If that is not the case, then the CH's transmit the data using BS spreading code. (Heinzelman et al., 2002)

Some channelization techniques like, such as having different types of frequencies for each cluster (e.g: FDMA) are also possible, but it includes lot of challenges. 


\subsubsection{First Order Radio Energy Model}

For calculating the dissipated energy that happens in network, with this protocol, the below mentioned radio model will be put to use.

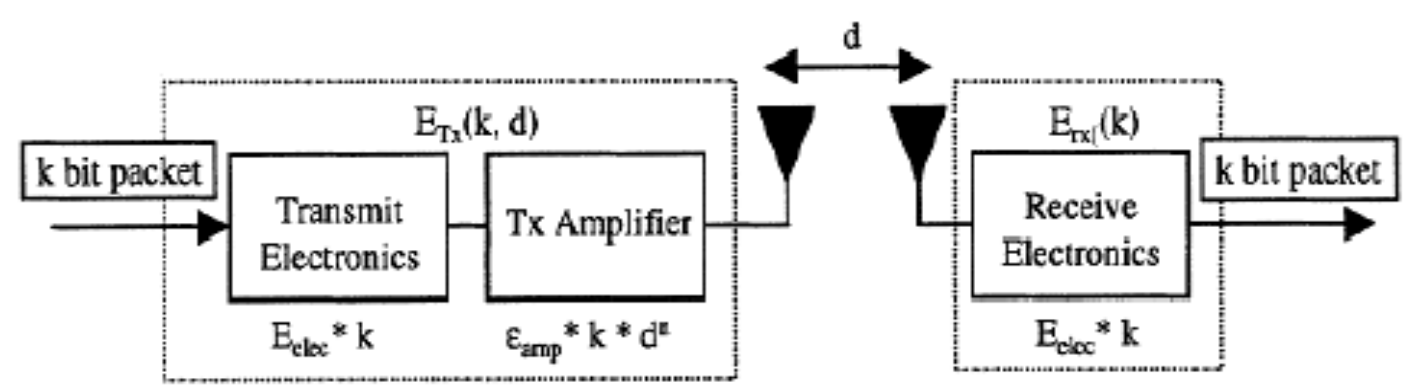

Figure 2.5: Radio Energy Model

(Elshrkawey, Elsmere, \& Wahed, 2018)

The dissipation of energy is done by the transmitter in order to run the components of radio and the amplifier. (Elshrkawey, Elsmere, \& Wahed, 2018)

Energy is also dissipated by the receiver to run the radio components of electronics in receiving.

Power loss models will be put to use, that depends upon the measured distance that lies among source and destination. Multipath model amplifier $\varepsilon_{m} d^{4}$, is the one that comes into calculation part, if the measured distance is more, when compared to the threshold distance. Free space model $\varepsilon_{f} d^{2}$ is used for lesser than threshold or cross-over distance.

To transmit, a message size of k-bit, with a distance d, the energy that gets dissipated, by radio is given by,

$$
\begin{aligned}
& E_{T X(k, d)}=E_{T X-e l e c}(k)+E_{T X-a m p(k, d)} \\
& =\left\{\begin{array}{cc}
k \times E_{\text {elec }}+k \times \varepsilon_{f} * d^{2}, & d<d_{0} \\
k \times E_{\text {elec }}+k \times \varepsilon_{m} \times d^{4}, & d \geq d_{0}
\end{array}\right.
\end{aligned}
$$

To receive a message of $\mathrm{k}$-bit, at a distance $\mathrm{d}$, then the energy expended by the radio is given by

$$
E_{R X}(k)=E_{R X-e l e c}(k)=k \times E_{\text {elec }}
$$

Equation 2.3

$E_{T X}$ : energy that is utilized for the transmission of packet

$E_{\text {elec }}$ : electronic energy required to run the radio components circuitry

$E_{R X}:$ required energy utilized for receiving the data packet

$d_{0}=\sqrt{\frac{\varepsilon_{f}}{\varepsilon_{m}}}$, which is named as threshold distance. 
The electronics energy, $E_{\text {elec }}$ depends upon several factors like filtering, modulation.

\subsection{Advantages of LEACH}

LEACH by nature is a complete, distributed routing protocol. The basic version of LEACH does not require any global routing information. Some of its advantages are

- The concept of clustering used by LEACH makes the system to prolong for a longer lifetime, when compared to direct transmission.

- $\mathrm{CH}$ minimizes correlated data locally by implementing data aggregation method that minimizes, the consumption of the energy by a significant amount.

- The time slots allotted to the non-CH sensors by the CHs, instructs them to go into sleep mode. This helps in avoiding the collisions inside the cluster and unrelated noise.

- The chances of becoming a $\mathrm{CH}$, to each node in the system, will be given equally, by $\mathrm{LEACH}$ protocol. Every node will get a chance of becoming $\mathrm{CH}$, at least once and non- $\mathrm{CH}$, so many times, till the death of sensor nodes. The $\mathrm{CH}$ 's rotation in a randomized manner is the reason, for the prolonged system lifetime.

Even though LEACH protocol does that, it still has lot of drawbacks and drawbacks which are in detailed here.

\subsection{Disadvantages and Limitations of LEACH}

- The concept of remaining energy of sensors after every round is not taken into account, in the process of selecting the $\mathrm{CHs}$, in the conventional LEACH protocol.

- Main problem of LEACH protocol is scalability. It is designed to perform well, in smaller regions, since in regions of larger size, sensors which are farther distance to sink, will result to high energy consumption, that too rapidly.

- The schedule allotted in the form of TDMA has some restrictions: Each $\mathrm{CH}$ will have its own slot to transmit packets of information in the allocated, time duration, despite of any new information is sensed.

- Some clusters, consists of higher number of sensors when compared to others. This unbalanced clusters causes to drain higher amount of energy than other clusters.

- This protocol takes this assumption, that all sensors consists of high battery energy that can be used to get communicated with BS, directly. When probability factor of selecting clusters is set to zero or hundred, sensors which are at a farther distance far away from the sink, will lose their energy rapidly and that region will go un sensed for the rest of the period of network operation.

- The basic version of LEACH protocol is simulated considering all nodes as homogeneous, which in practical scenario is different.

- Security is one main aspect that has not been looked into, so far for this protocol. Data privacy is an important concern, when used in sensitive real-world applications. 


\subsection{Lifetime of a Sensor Node}

Sensor node's lifetime is defined as the state at which, it depletes its energy to a threshold known as critical energy, at which the node becomes incapable to perform any transmission or reception for 1-bit of data. (Ok et al., 2009)

The sensor node will be treated as dead node, once it depletes its energy to its critical energy, after the network operation begins. Since the LEACH protocol is taken as network of homogeneous sensors, critical energy is same for all of them.

In the LEACH protocol (Lindsey \& Raghavendra, 2002) to reduce the complexity, the critical energy of each sensor node is put to zero, as a pre-energy calculation.

But, when it comes to practical scenario, there will be predetermined critical energy, which depends upon different factors, like hardware configuration of the sensor node, the power of transmitter amplifier etc.

\subsection{Related Research Work}

Long et al. (2011) had proposed an algorithm. It depends upon assistant cluster head approach. A dynamic method is established in checking the ability of a sensor node to become a cluster head or not, that depends upon the geographical location of the node, and the number of members in each cluster as well the energy that is left in the node after a round. This approach has been successful in, extending the system lifetime by minimizing the consumption of energy by the non- $\mathrm{CH}$ nodes in a cluster.

The main drawback of this approach is, it requires complex operations to be executed, that causes high delays.

Junping et al. (2008) had proposed a new algorithm. Clusters are formed without the requirement of any global information, but it depends upon random timer. This algorithm still suffers from high energy gap consumption between sensor nodes and their $\mathrm{CHs}$.

Ren et al. (2010) had proposed a new algorithm. It is based on unequal clustering scheme. It solves the problem of minimizing the hotspot, like in LEACH. Concentric circles of unequal size are considered as clusters. Cluster size decreases, if we move far from the sink. $\mathrm{CH}$ selection is done, by depending upon the factors like remaining energy on the node, weight factor. Problem with intra cluster communication, for clusters near to sink.

Al-Maaqbeh et al. (2012) had proposed a new algorithm. Concept of fuzzy logic has been used in this protocol. It is done by modifying the existing basic LEACH. Consists of fuzzier, defuzzifier, fuzzy interference system and rules. The concept of fuzzy logic, is used and applied on the count of sensor nodes as well as density of the network. Helps in finding out initial CHs. This algorithm does not consider energy into consideration for calculation.

Mahmood et al. (2013) proposed using different signal amplifications in two values, for inter and intra cluster communications. Significant amount of energy is saved. Changes in selection of $\mathrm{CH}$ process is also made. $\mathrm{CH}$ is not changed in every round. A predefined threshold is used and compared against with, to choose a new $\mathrm{CH}$. Amplification of two different signals for this purpose is a difficult problem. 
Chen et al. (2013) proposed taking uncertainty in number of CHs into account and their location. Optimal CHs are given by the equation proposed. Ensures uniform distribution of CHs. Performs well when compared to existing basic LEACH, on the parameters of consumption of energy and system lifetime.

Bsoul et al. (2013) proposed using multi-hop and centralized approach. Sink calculates the threshold. Sink chooses, the one having higher remaining energy, as the $\mathrm{CH}$. Minimum distance to $\mathrm{CH}$, is calculated. Calculates distance between two $\mathrm{CHs}$ and if it is found that the measured distance, is higher or equal to, then second node is chosen as $\mathrm{CH}$, among them.

Salim et al. (2014) proposed to reduce the energy difference between $\mathrm{CH}$ and members of that cluster. Main target is to minimize intra cluster communication costs. Pre-steady phase is added to the remaining old phases. Main issues are scalability, control overhead.

Katiyar et al. (2011) proposed to solve, high variations in cluster size. Performance of protocol is affected by this. Concept of far zone is introduced. Sensor nodes other than CHs, send their minimum power to their respective cluster heads. This helps in solving the issue of variations in the sizes of clusters.

$\mathrm{Xu}$ et al. (2012) proposed on the issue of optimum number of CHs. Round time is varied in every round. $\mathrm{CH}$ is chosen based on the higher remaining residual energy. Main advantage is energy across the network is distributed uniformly.

Zhao et al. (2012) proposed the modification of LEACH protocol by cluster head selection and multi-hop routing. The proposed protocol is able to improve the stability period and network lifetime than basic LEACH protocol. Drawbacks are non-uniform distribution of cluster heads and also selection of a node as cluster head based on the random number, without considering any other factors. 


\section{CHAPTER 3 \\ METHODOLOGY}

\subsection{Contribution}

After detailed study, for the improvement of LEACH protocol through its derivatives, the possibility of proposed approach is derived.

The resulted protocol will be simulated along with the original LEACH protocol and the outputs will be compared based on network's stability period and total network lifetime as the parameters in order to check the effectiveness of proposed approach.

The contributed work of the modified approach can be used by the researchers for further analysis like adding security to the approach from or deploying it in different scenarios etc.

\subsection{Proposed Approach}

The proposed method has one simple modification to the existing LEACH. The existing basic LEACH protocol cannot guarantee, distribution of $\mathrm{CHs}$ on the entire network. In this modification, this problem will be solved to major extent. The sensor network will be divided into number of rectangular sub-regions, depending upon the probability of the $\mathrm{CHs}$, and number of nodes in the network, which are predetermined at the beginning of the operation of the network. This makes the sensor nodes in the network, to have a cluster head in their vicinity for every round, unlike existing basic LEACH protocol, which might have all the $\mathrm{CHs}$, to be in the same region for several rounds, because of the process followed in the CH's selection.

\subsection{Cluster Head Selection Modification}

Random deployment of sensors is implemented in a geographic region of predetermined dimensions. In this modified approach, it divides the whole network region into sub regions. A cluster head will be selected from each sub-region, for every round. This makes the $\mathrm{CHs}$ in the network more distributed or more uniformly located in the whole network for every round. This by obvious, makes, any of the region go un-sensed, till the last node death in that region.

- Sensors nodes are spread on the entire network in a random based scenario.

- Let ' $L$ ' and ' $W$ ' be the number of length and breadth of the sensor region

- 'numRx' be the number of segments on each side

- Calculate numRx $=\operatorname{sqrt}(\mathrm{p} \times \mathrm{N})$ where ' $\mathrm{p}$ ' is the probability of cluster heads given and $\mathrm{N}$ is the total number of nodes in the network.

- Then $d x=L /$ numRx and $d y=W / n u m R x$ be the sub-region length and breadth respectively

- Divide the sensor field into sub-regions.

- Number of sub-regions in the network will be equal to (numRx) $\times($ numRx $)$

- Each sub-region acts as individual wireless sensor network

- In the setup phase, select a random node as $\mathrm{CH}$ from each-sub region. 
- All the rest of the nodes in the sub-region, join that $\mathrm{CH}$ and forms clusters for each sub-region

- In the steady state phase, sensor nodes send their sensed data to their CHs and the $\mathrm{CHs}$, transmit the data to the base station. This completes a round.

- In the next round, just select a random node again, from each sub-region to become a cluster head, and repeat both the phases one by one, setup and steady state.

- Repeat the steps, until every sensor node get to be become a cluster head once, in each sub-region.

- Once every node in each sub-region gets to be a $\mathrm{CH}$, then consider all of them as normal nodes and continue the process

- Continue this process of selection of cluster heads, till the death of last node in each sub-region.

- The sensor network is considered as dead, once all the nodes in the network are dead.

\subsection{Methdology for the Proposed Approach}

This section depicts the methdology for the proposed approach. Flow chart is shown below. 


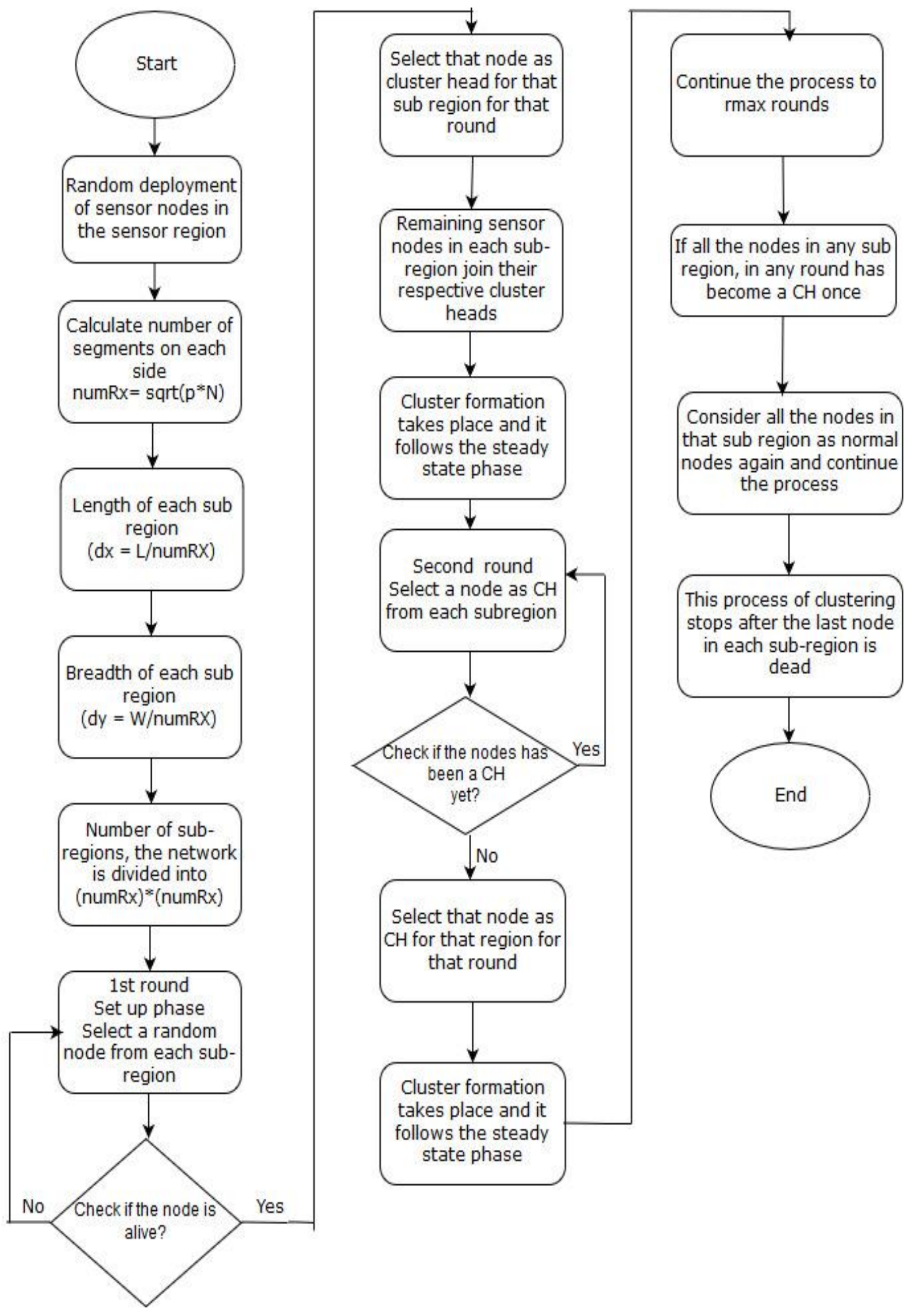

Figure 3.1: Methodology of the proposed modified approach 


\subsection{Pseudocode for Proposed Cluster Head Selection Modification:}

Initialize WSN parameters

$\mathrm{N}=$ Total number of nodes in the network

$\mathrm{W}=$ Width of the network

$\mathrm{L}=$ Length of the network

$\mathrm{p}=$ Probability of cluster heads

Rmax $=$ maximum number of simulated rounds

$\mathrm{Ei}=$ Intial energy in each node

Initialize all energy parameters

(SX, SY) Base station position

Pre allocations for calculations

Ecrit $=$ critical energy left in each node to call it alive

Ncritcal $=$ Critical number of nodes left to stop the simulation

Status of nodes; 0: Alive; 1; Dead

Process:

Deploy ' $\mathrm{N}$ ' nodes randomly in the given area

Simulations for each round:

Declarations:

$\mathrm{dx}=$ length of the sub-region divided

$\mathrm{dy}=$ width of the sub-region divided

$\mathrm{X}=$ Set of $\mathrm{X}$-axis coordinates for all the ' $\mathrm{N}$ ' nodes

$\mathrm{Y}=$ Set of $\mathrm{Y}$ - axis coordinates for all the ' $\mathrm{N}$ ' nodes

numRx $=$ number of segments on each side

$I_{n}=$ Unique number for each sensor node from ( 1 to $\mathrm{N}$ )

Simulation process for each round:

Loop: for $\mathrm{r}=1$ to $\operatorname{rmax}$

/* Dividing sensor network into sub-regions*/

Calculate numRx $=\operatorname{sqrt}(\mathrm{p} \times \mathrm{N}) ; / *$ number of segments on each side*/ Round it off to

the nearest integer towards zero

Calculate $\mathrm{dx}=$ Divide L by numRx; /*length of each sub-region divided*/

Calculate dy = Divide $\mathrm{W}$ by numRx; /* width of each sub-region divided*/

$\mathrm{X}=X_{i=1: N}$ set of $\mathrm{X}$-axis coordinates for all ' $\mathrm{N}$ ' nodes

$\mathrm{Y}=Y_{i=1: N}$ set of $\mathrm{y}$-axis coordinates for all ' $\mathrm{N}$ ' nodes

/*Select a node as cluster head from each sub-region*/

Loop: for $\mathrm{i}=1$ to numRx

for $\mathrm{j}=1$ to numRx 
choose a node from each sub-region having higher unique number

If chosen node is alive,

Then

select it as $\mathrm{CH}$ for that sub-region, for that round

Else

choose other node from sub-region, having next higher unique number Continue;

/*Update cluster head for every round and for each sub-region*/

Check if the selected node is alive or dead

If

Chosen node from each sub-region is alive

Then

Choose it in the process of clustering

Else

Select other node in each sub-region, in the same order Continue;

If

All the nodes in a sub-region are dead

Then

Choose no node as $\mathrm{CH}$ from that region and go to next cluster and continue the process

Continue;

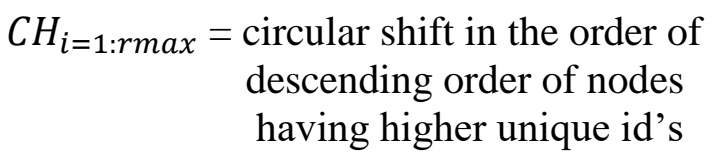

end

end

end 


\subsection{Simulation Parameters for Scenario 1}

Table 3.1 Simulation parameters (i)

(Lindsey \& Raghavendra, 2002)

\begin{tabular}{|l|l|}
\hline No of nodes & $\mathrm{N}=50,100,150$ \\
\hline Probability of CHs $(\mathrm{p})$ & $\begin{array}{l}\mathrm{p}=0.05 \text { for } \mathrm{N}=100,150 \& \mathrm{~N}=0.1 \text { for } \\
\mathrm{N}=50\end{array}$ \\
\hline Network size $(\mathrm{L} \times \mathrm{W})$ & $\begin{array}{l}50 \times 50 \text { square meter } ; 100 \times 100 \text { square } \\
\text { meter }\end{array}$ \\
\hline Initial energy of each node $E_{i}$ & $E_{i}=1 \mathrm{~J}$ \\
\hline $\begin{array}{l}\text { Base station location for } 50 \times 50 \text { network } \\
\text { size }\end{array}$ & $(25,150)$ \\
\hline $\begin{array}{l}\text { Base station location for } 100 \times 100 \text { network } \\
\text { size }\end{array}$ & $(50,300)$ \\
\hline Energy model & First order radio energy model \\
\hline Multipath model amplifier & $\epsilon_{a m p}=100 \mathrm{pJ} / \mathrm{bit} / \mathrm{m}^{2}$ \\
\hline Packet size & $2000 \mathrm{bits}, 100 \mathrm{bits}$ \\
\hline Energy for data aggregation $E_{D A}$ & $E_{D A}=5 \mathrm{~nJ} / \mathrm{bit}$ \\
\hline Energy for data transmission & $E_{t r}=50 \mathrm{~nJ} / \mathrm{bit}$ \\
\hline Energy for data receiving & $E_{r e}=50 \mathrm{~nJ} / \mathrm{bit}$ \\
\hline Packet transmission rate & $1 \mathrm{packet} / \mathrm{round}$ \\
\hline Deployment type & Random based deployment \\
\hline Number of simulations per one data point & 10 \\
\hline
\end{tabular}




\subsection{Simulation Parameters for Scenario 2}

Table 3.2 Simulation parameters (ii)

\begin{tabular}{|l|l|}
\hline No of nodes & $\mathrm{N}=100$ \\
\hline Probability of CHs $(\mathrm{p})$ & $\mathrm{p}=0.05$ \\
\hline Network size $(\mathrm{L} \times \mathrm{W})$ & $100 \times 100$ square meter \\
\hline Initial energy of each node $E_{i}$ & $E_{i}=0.03 \mathrm{~J}$ \\
\hline $\begin{array}{l}\text { Base station location for } 100 \times 100 \\
\text { network size }\end{array}$ & $(150,50)$ \\
\hline Energy model & First order radio energy model \\
\hline Multipath model amplifier & $\epsilon_{a m p}=100 \mathrm{pJ} / \mathrm{bit} / \mathrm{m}^{2}$ \\
\hline Packet size & $100 \mathrm{bits}$ \\
\hline Energy for data aggregation $E_{D A}$ & $E_{D A}=5 \mathrm{~nJ} / \mathrm{bit}$ \\
\hline Energy for data transmission & $E_{t r}=50 \mathrm{~nJ} / \mathrm{bit}$ \\
\hline Energy for data receiving & $E_{r e}=50 \mathrm{~nJ} / \mathrm{bit}$ \\
\hline Packet transmission rate & $1 \mathrm{packet} / \mathrm{round}$ \\
\hline Deployment type & Random based deployment \\
\hline Number of simulations per one data point & 10 \\
\hline
\end{tabular}

\subsection{Simulation Environment}

The proposed approach will be simulated using MATLAB 2017a. Sensors are spread in a random fashion. Network has hundred sensors in $100 \times 100 \mathrm{~m}^{2}$ and $50 \times 50 \mathrm{~m}^{2}$ dimensions. The initial energy of every sensor node is $1 \mathrm{~J}, 0.03 \mathrm{~J}$.

In this study, it will be considered that all sensors are scattered on the 2-D coordinate system between $(\mathrm{x}=0, \mathrm{y}=0)$ and $(\mathrm{x}=50, \mathrm{y}=50) ;(\mathrm{x}=0, \mathrm{y}=0)$ and $(\mathrm{x}=100, \mathrm{y}=100)$; and sink is at $(25,150)$ and at $(50,300),(150,50)$ respectively, in the network regions.

2000 bits and 100 bits are the packet sizes for scenario 1 and scenario 2 respectively. For energy dissipations, the radio energy model is followed. The energy dissipated to receive or transmit one bit of data is taken as $50 \mathrm{~nJ} / \mathrm{bit}$. The energy for data fusion is taken as $5 \mathrm{~nJ} / \mathrm{bit}$. Multipath model amplifier is taken as $100 \mathrm{pJ} / \mathrm{bit} / \mathrm{m}^{2}$.

This modified approach is simulated with these parameters and compared with the existing basic LEACH protocol (Lindsey \& Raghavendra, 2002) and existing ILEACH protocol (Zhao et al., 2012) 


\section{CHAPTER 4 \\ SIMULATION RESULTS \& DISCUSSIONS}

\subsection{Simulation Environment}

Simulation of modified protocol is done with two scenarios. WSN consisting of 100 sensors, scattered in a random fashion in $50 \mathrm{~m} \times 50 \mathrm{~m}, 100 \mathrm{~m} \times 100 \mathrm{~m}$, varying the beginning energy of each node with $1 \mathrm{~J}, 0.03 \mathrm{~J}$. It is compared against the existing LEACH protocol (Lindsey \& Raghavendra, 2002) and existing ILEACH protocol (Zhao et al., 2012) with simulation parameter of scenario 1 and scenario 2 respectively. Network lifetime parameters are taken into consideration, for evaluating the performance of modified protocol.

\subsection{Performance Evaluation Metrics}

Network Lifetime: It is defined as the total time period from starting of the network operation to the death of last sensor node in the network. (Yousaf et al., 2016)

Stability Period: It is defined as the time period from starting of the network operation to the death of first sensor node in the network. (Yousaf et al., 2016)

Instability Period: It is defined as the time period between first node death to last node death in the network. (Batra \& Kant, 2016)

Network Lifetime $=$ Stability period + Instability period. (Yousaf et al., 2016)

HNA: Half of the nodes alive in the network

\subsection{Simulation Results}

This part depicts the graphs of lifetime of the network with bar graphs and line graphs indicating percentage of node deaths including first node death and last node death.

Performance results are taken as an average of 10 simulations, which were performed

Bar graphs and line graphs indicating first node deaths, $20 \%$ of the node deaths, $50 \%$ of the node deaths and $100 \%$ of the node deaths.

Stability period and lifetime of system are noted down to evaluate performance of proposed protocol. 


\subsection{Deployment Scenario A}

A snapshot of simulation scenario for $50 \times 50 \mathrm{~m}^{2}$ size network. Location of sink at $(25,150)$.

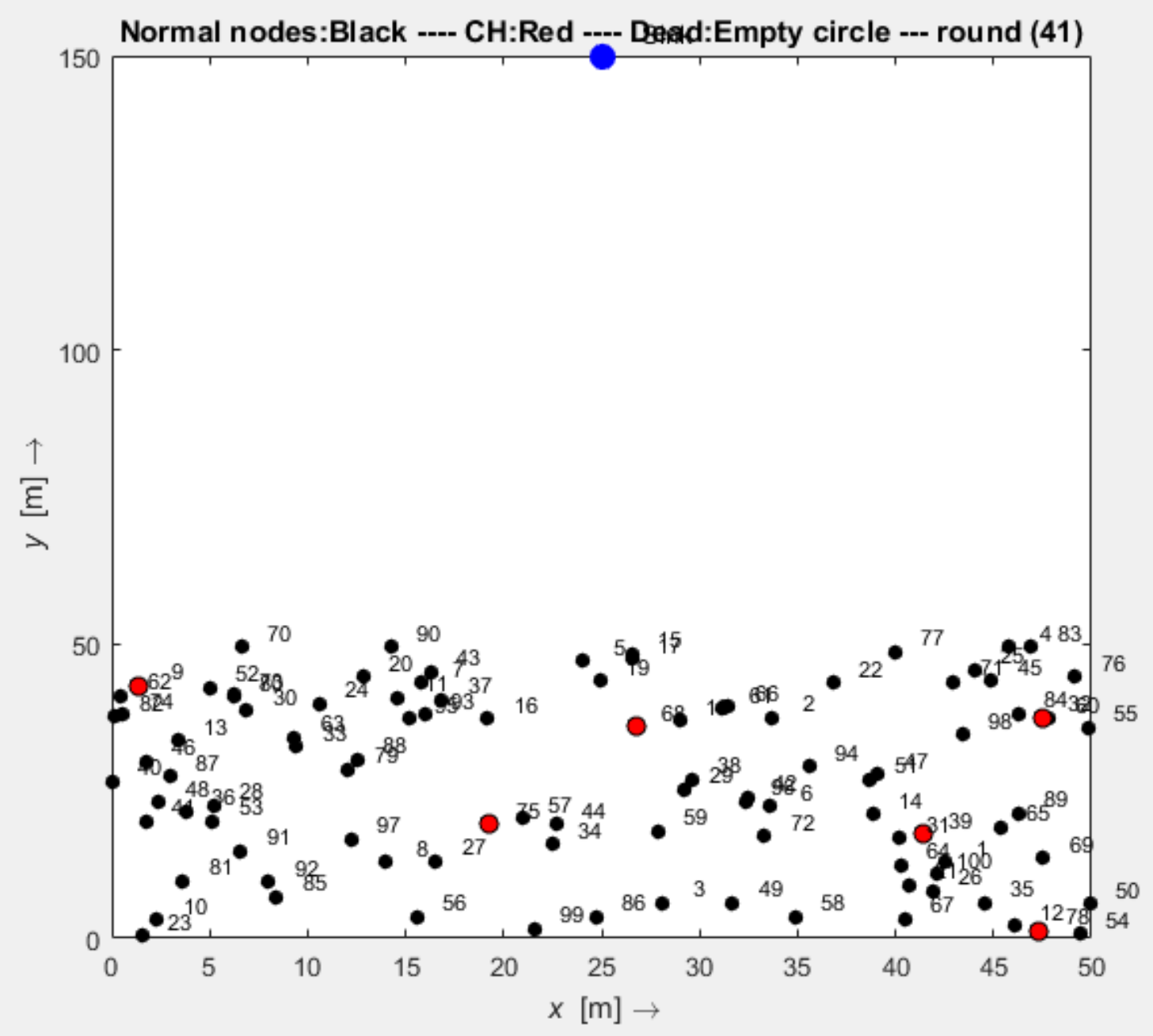

Figure 4.1: Deployment scenario for $50 \times 50 \mathrm{~m}^{2}$ size network 


\subsection{Deployment Scenario B}

A snapshot of simulation scenario for $100 \times 100 \mathrm{~m}^{2}$ size network. Location of sink at $(50,300)$.

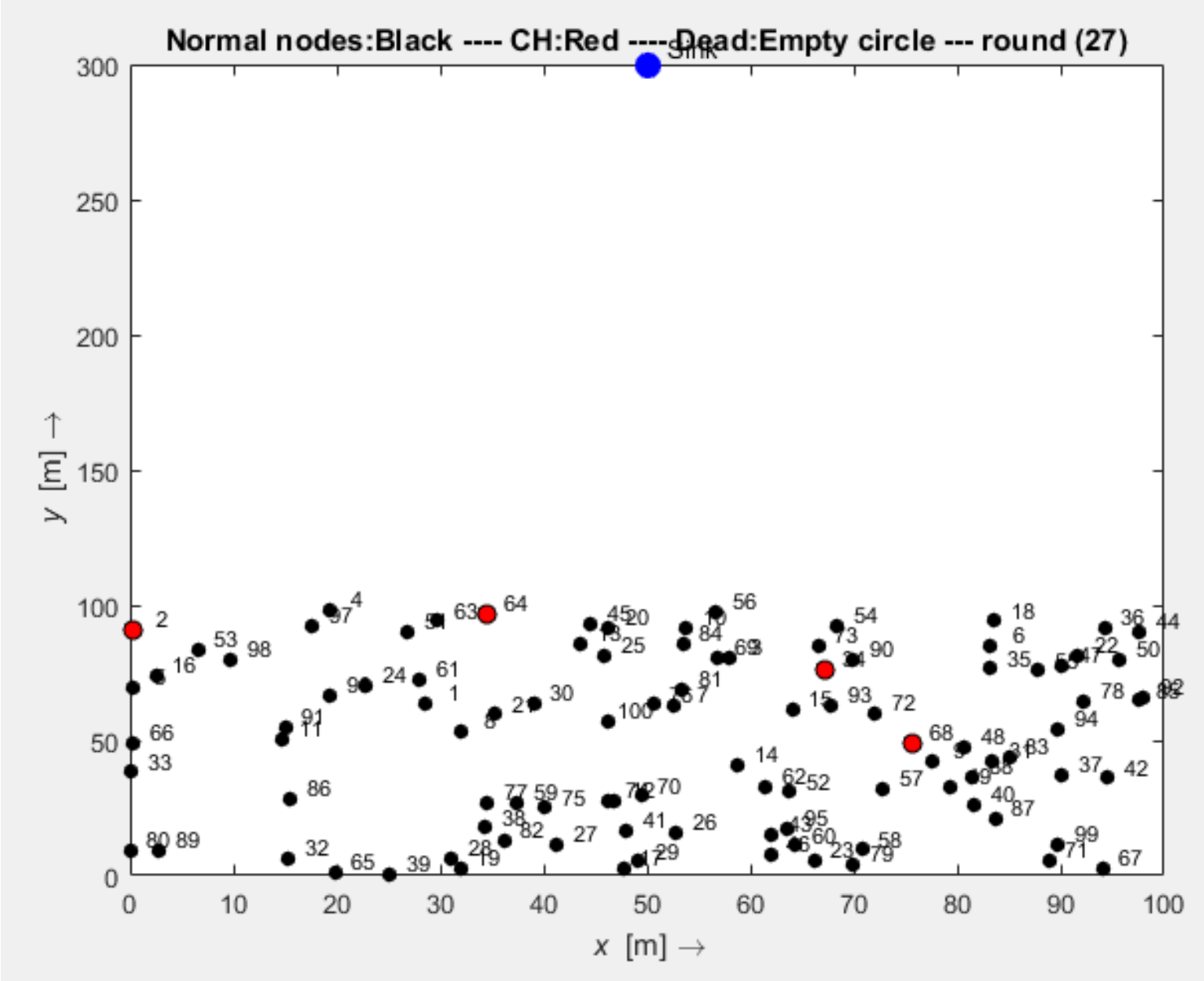

Figure 4.2: Deployment scenario for $100 \times 100 \mathrm{~m}^{2}$ size network. 


\subsection{Performance Graphs}

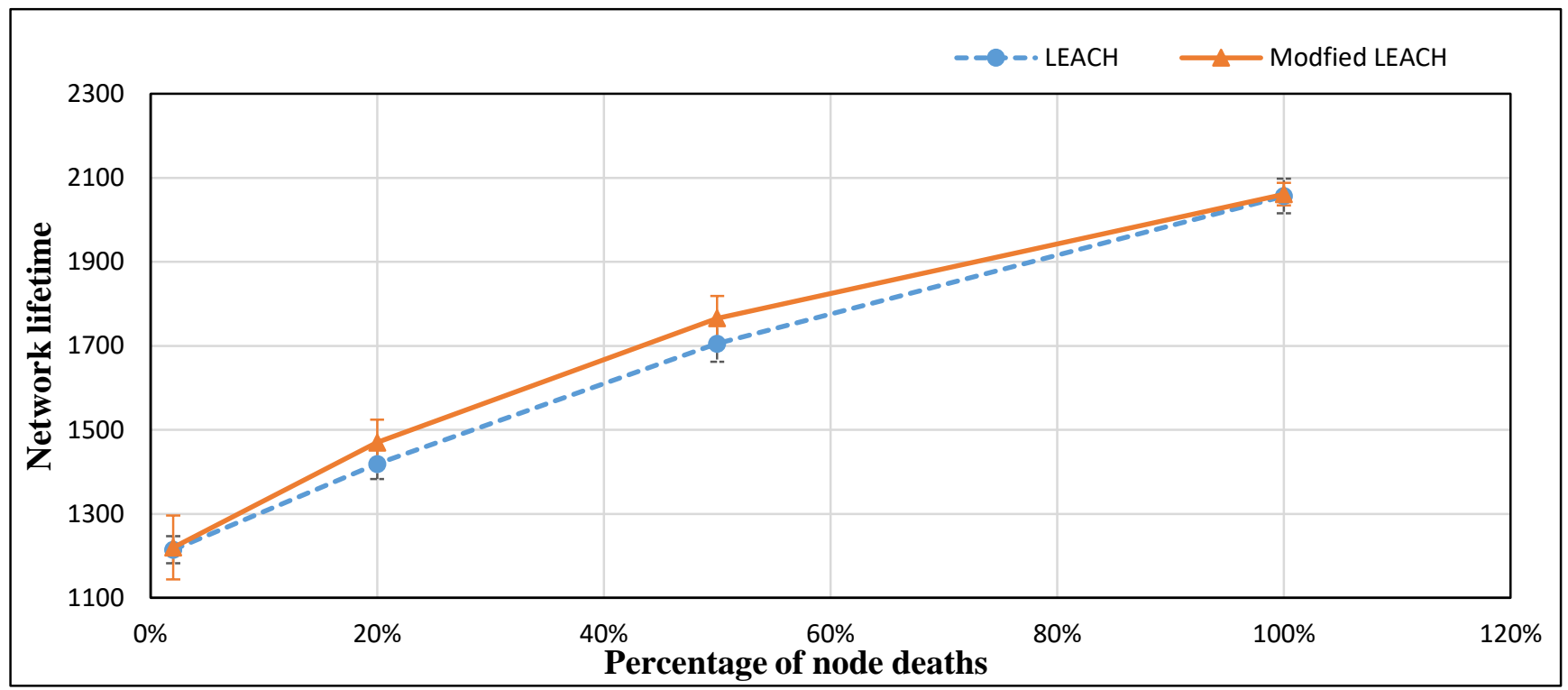

Figure 4.3: Performance results of LEACH and modified LEACH of 50 nodes in $50 \mathrm{~m} \times 50 \mathrm{~m}$ network size, with initial energy $=1 \mathrm{~J} /$ node, $\mathrm{p}=0.1$ (i)

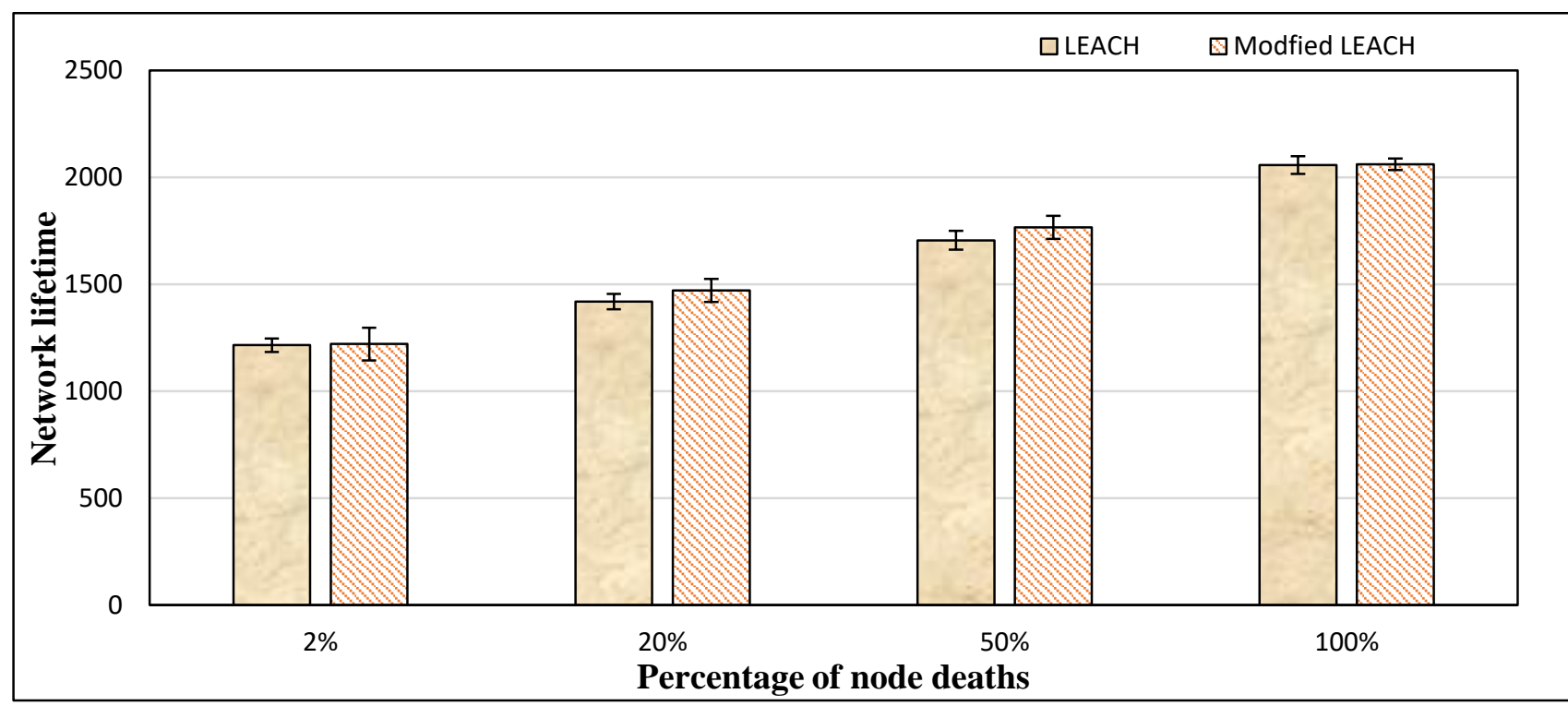

Figure 4.4: Performance results of LEACH and modified LEACH of 50 nodes in $50 \mathrm{~m} \times 50 \mathrm{~m}$ network size, with initial energy $=1 \mathrm{~J} /$ node, $\mathrm{p}=0.1$ (ii) 
Table 4.1: Network lifetime of LEACH and modified LEACH of 50 nodes in $50 \mathrm{~m} \times 50 \mathrm{~m}$ network size, initial energy $=1 \mathrm{~J} /$ node

\begin{tabular}{|l|l|l|l|l|}
\hline Protocol & $2 \%$ of node death & $20 \%$ of node death & $50 \%$ of node death & $100 \%$ of node death \\
\hline LEACH & 1214.6 & 1419 & 1705.4 & 2056.8 \\
\hline $\begin{array}{l}\text { Modified } \\
\text { LEACH }\end{array}$ & 1220.1 & 1470.2 & 1765.7 & 2061.1 \\
\hline
\end{tabular}

The above results are an average of 10 simulations that were performed.

Average stability period of LEACH protocol $=1214.6$ rounds

Average stability period of Modified LEACH protocol $=1220.1$ rounds

Average network lifetime of LEACH $=2056.8$ rounds

Average network lifetime of Modified LEACH protocol $=2061.1$ rounds

In a network size of 50 nodes, $2 \%$ of node deaths include the first node death (FND) of the network. In a $50 \mathrm{~m} \times 50 \mathrm{~m}$ network of 50 nodes, the modified LEACH protocol is able to improve the stability period of the network and total lifetime of the network, slightly better than basic LEACH protocol.

This can be used in the applications, where longer stability period of the network is required as well as longer total network lifetime is the requirement. 


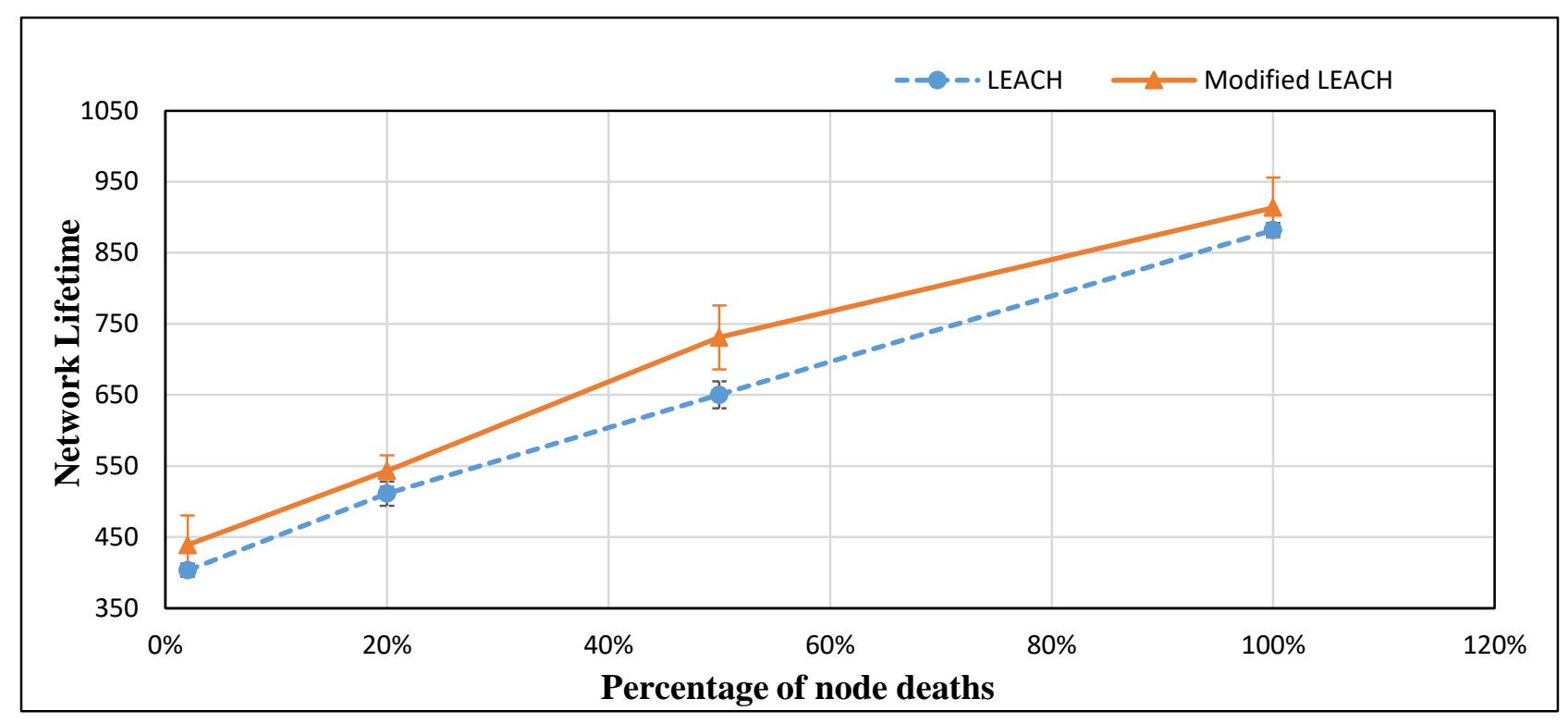

Figure 4.5: Performance results of LEACH and modified LEACH of 50 nodes in $100 \mathrm{~m} \times 100$ network size, with initial energy $=1 \mathrm{~J} /$ node, $\mathrm{p}=0.1$ (i)

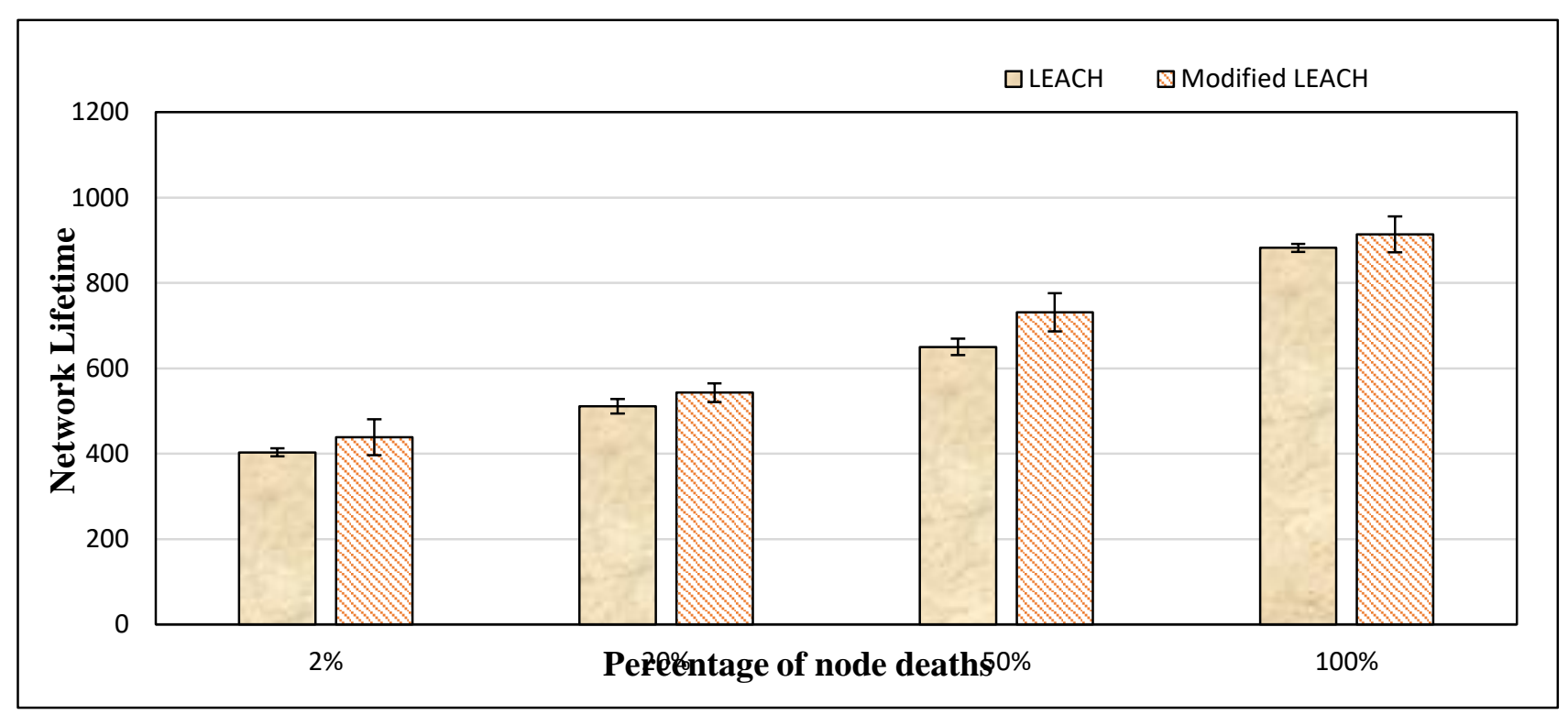

Figure 4.6: Performance results of LEACH and modified LEACH of 50 nodes in $100 \mathrm{~m} \times 100$ network size, with initial energy $=1 \mathrm{~J} /$ node, $\mathrm{p}=0.1$ (ii) 
Table 4.2: Network lifetime of LEACH and modified LEACH of 50 nodes in $100 \mathrm{~m} \times 100 \mathrm{~m}$ network size, with initial energy $=1 \mathrm{~J} /$ node

\begin{tabular}{|l|l|l|l|l|}
\hline Protocol & $2 \%$ of node death & $20 \%$ of node death & $50 \%$ of node death & $100 \%$ of node death \\
\hline LEACH & 403.4 & 511.3 & 650.3 & 882.2 \\
\hline $\begin{array}{l}\text { Modified } \\
\text { LEACH }\end{array}$ & 438.8 & 543.2 & 731.2 & 913.6 \\
\hline
\end{tabular}

The above results are plotted taking an average of 10 simulations that were performed.

Average stability period of LEACH protocol $=403.4$ rounds

Average stability period of Modified LEACH protocol $=538.8$ rounds

Average network lifetime of LEACH protocol $=882.2$ rounds

Average network lifetime of Modified LEACH protocol $=913.6$ rounds

In a 50 nodes network, $2 \%$ of the node deaths indicate first node death (FND) in the network. In a network size of $100 \mathrm{~m} \times 100 \mathrm{~m}$ with 50 nodes, modified LEACH protocol is able to improve the stability period as well as the overall lifetime of the network when compared to basic LEACH protocol. 


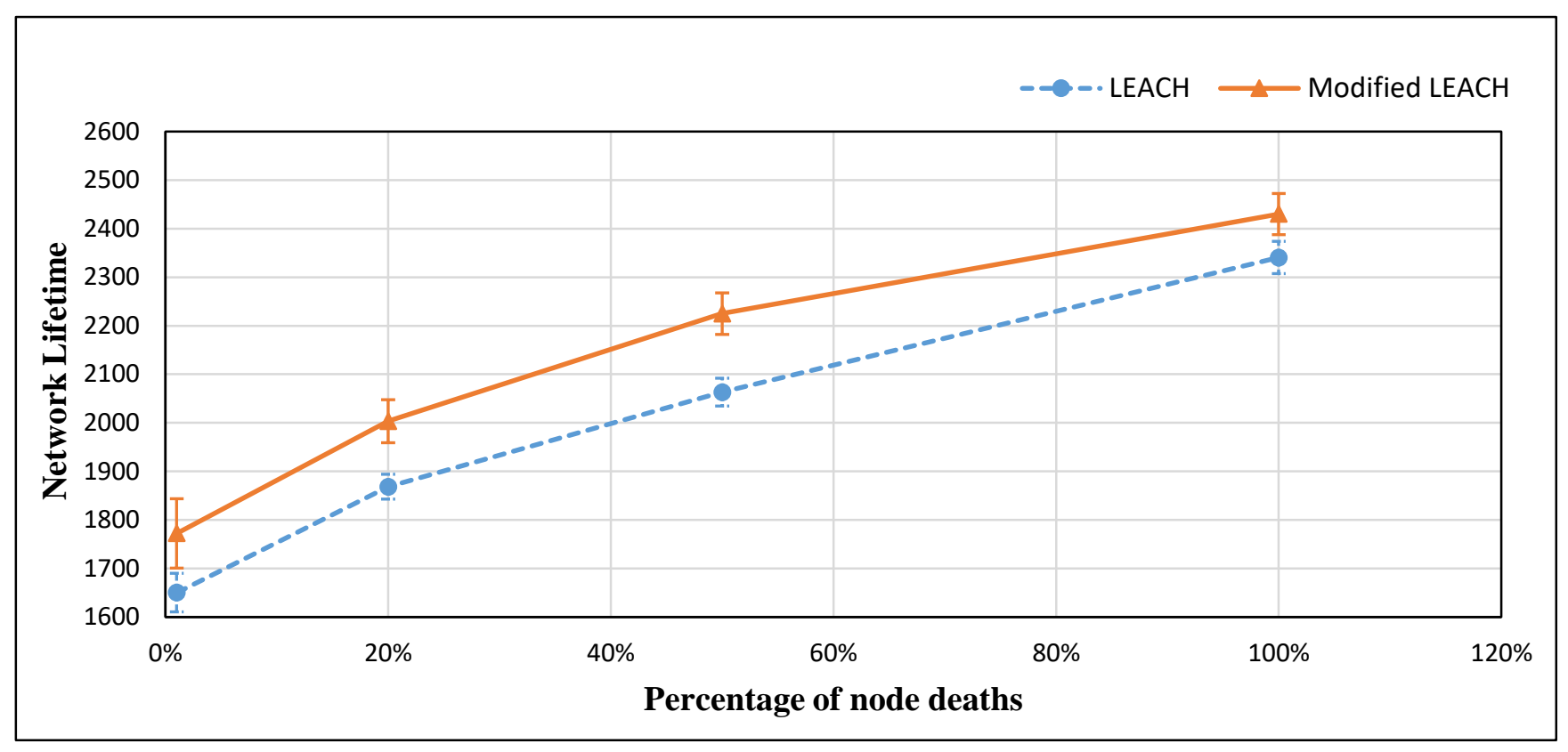

Figure 4.7: Performance results of LEACH and modified LEACH of 100 nodes in $50 \mathrm{~m} \times 50 \mathrm{~m}$ network size, with initial energy $=1 \mathrm{~J} /$ node, $\mathrm{p}=0.05$ (i).

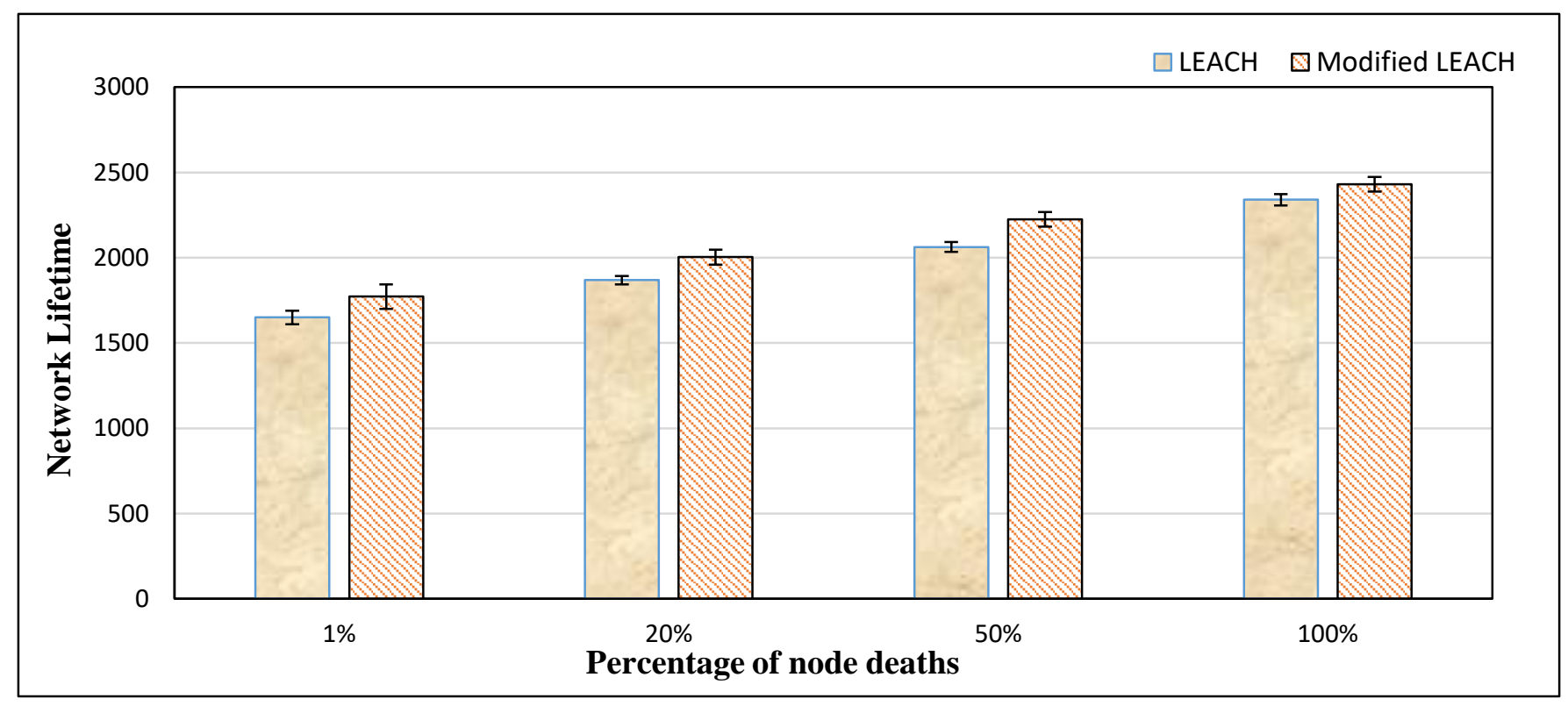

Figure 4.8: Performance results of LEACH and modified LEACH of 100 nodes in $50 \mathrm{~m} \times 50 \mathrm{~m}$ size with initial energy $=1 \mathrm{~J} /$ node, $\mathrm{p}=0.05$ (ii) 
Table 4.3: Network lifetime of LEACH and modified LEACH of 100 nodes in 50m $\times 50 \mathrm{~m}$ network size, initial energy $=1 \mathrm{~J} /$ node

\begin{tabular}{|l|l|l|l|l|}
\hline Protocol & $1 \%$ of node death & $20 \%$ of node death & $50 \%$ of node death & $100 \%$ of node death \\
\hline LEACH & 1649.9 & 1868.3 & 2063.2 & 2340.5 \\
\hline $\begin{array}{l}\text { Modified } \\
\text { LEACH }\end{array}$ & 1772.1 & 2003.3 & 2224.9 & 2430.3 \\
\hline
\end{tabular}

The above results are plotted on an average of 10 simulations that were performed.

Average stability period of LEACH protocol $=1649.9$ rounds

Average stability period of modified LEACH protocol $=1772.1$ rounds

Average network lifetime of $\mathrm{LEACH}$ protocol $=2340.5$ rounds

Average network lifetime of modified LEACH protocol $=2430.3$ rounds

In a 100 nodes network, $1 \%$ of the node deaths indicate first node death in the network (FND). In a network of $50 \mathrm{~m} \times 50 \mathrm{~m}$ of 100 nodes, modified LEACH is able to improve stability period as well as the overall lifetime of the network, when compared to basic LEACH protocol. 


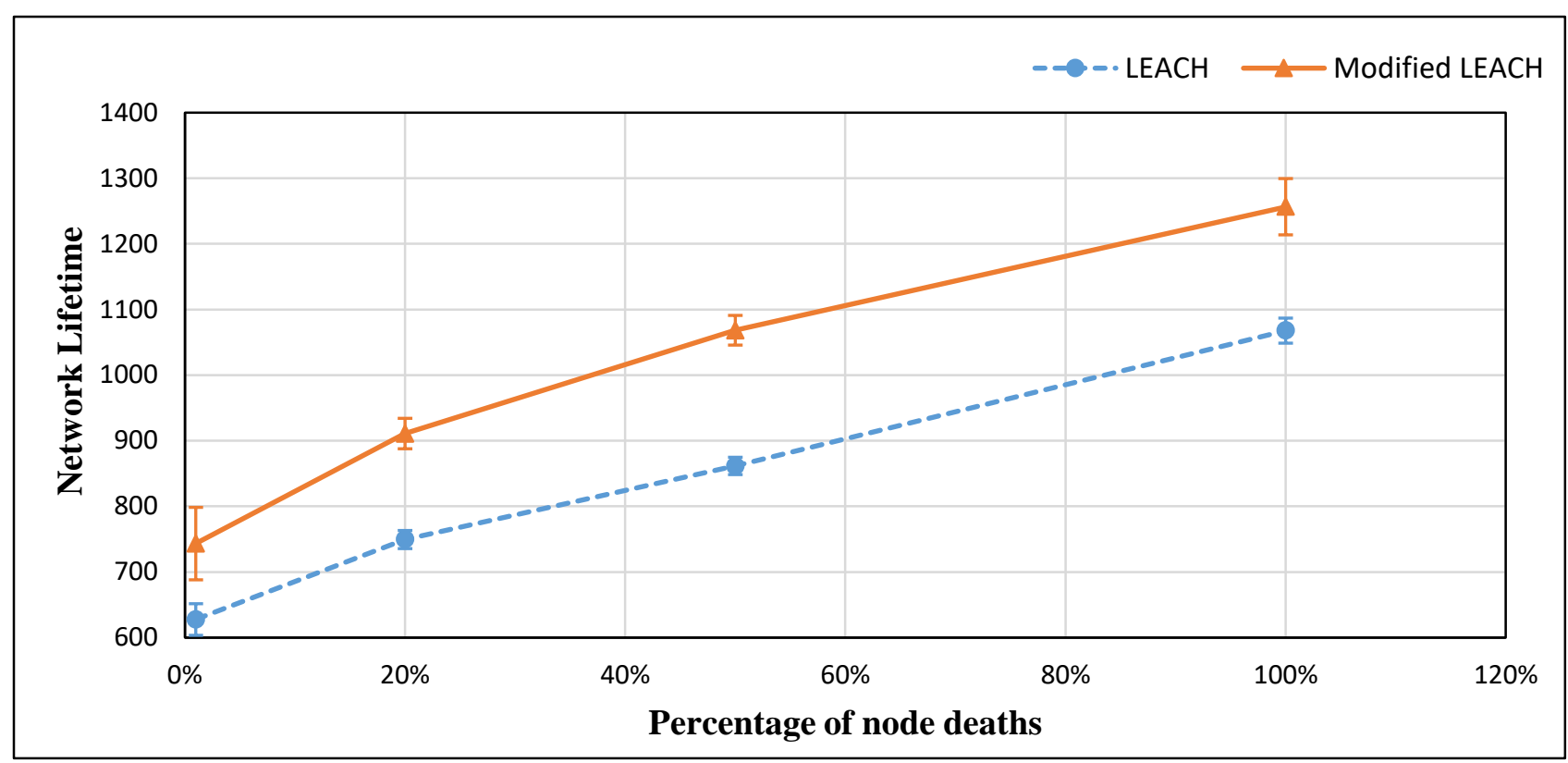

Figure 4.9: Performance results of LEACH and modified LEACH of 100 nodes in $100 \mathrm{~m} \times 100 \mathrm{~m}$ network size with initial energy $=1 \mathrm{~J} /$ node, $\mathrm{p}=0.05$ (i)

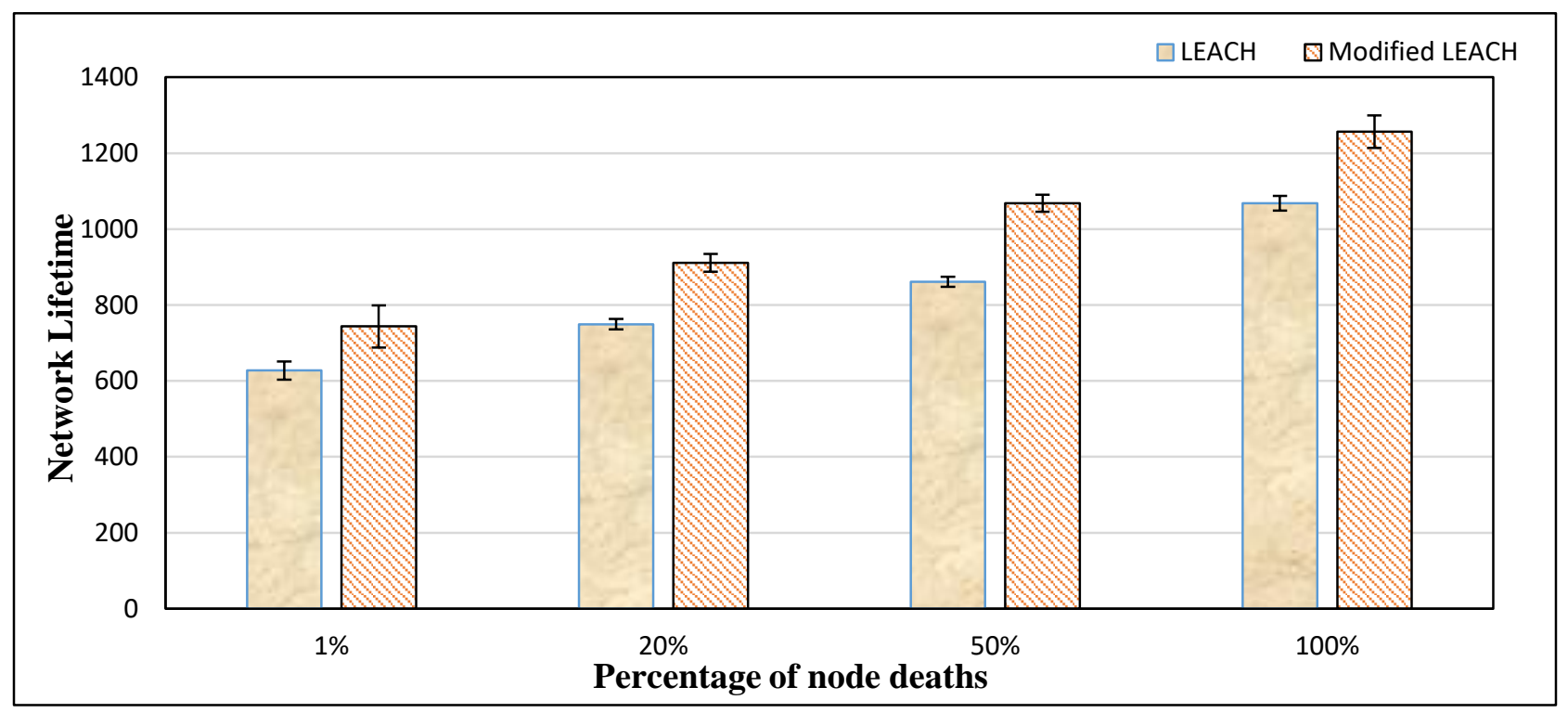

Figure 4.10: Performance results of LEACH and modified LEACH of 100 nodes in $100 \mathrm{~m} \times 100 \mathrm{~m}$ network size, with initial energy $=1 \mathrm{~J} /$ node, $\mathrm{p}=0.05$ (ii) 
Table 4.4: Network lifetime of LEACH and modified LEACH of 100 nodes in $100 \mathrm{~m} \times 100 \mathrm{~m}$ network size, with initial energy $=1 \mathrm{~J} /$ node

\begin{tabular}{|l|l|l|l|l|l|}
\hline Protocol & $\begin{array}{l}1 \% \text { of node } \\
\text { deaths }\end{array}$ & $\begin{array}{l}20 \% \text { of node } \\
\text { deaths }\end{array}$ & $\begin{array}{l}50 \% \text { of node } \\
\text { deaths }\end{array}$ & $100 \%$ of node deaths \\
\hline LEACH & 627.7 & 749.5 & 861.5 & 1068 \\
\hline $\begin{array}{l}\text { Modified } \\
\text { LEACH }\end{array}$ & 743.5 & 910.8 & 1068.4 & 1256.4 \\
\hline
\end{tabular}

The above results are plotted taking an average of 10 simulations that were performed.

Average stability period of LEACH protocol $=627.7$ rounds

Average stability period of Modified LEACH protocol $=749.5$ rounds

Average network lifetime of LEACH protocol $=1068$ rounds

Average network lifetime of Modified LEACH protocol $=1256.4$ rounds

In a network of 100 nodes, $1 \%$ of node deaths indicate the first node death in the network. In this $100 \mathrm{~m} \times 100 \mathrm{~m}$, of 100 nodes, modified LEACH protocol is able to improve the stability period as well as the overall lifetime of the network. 


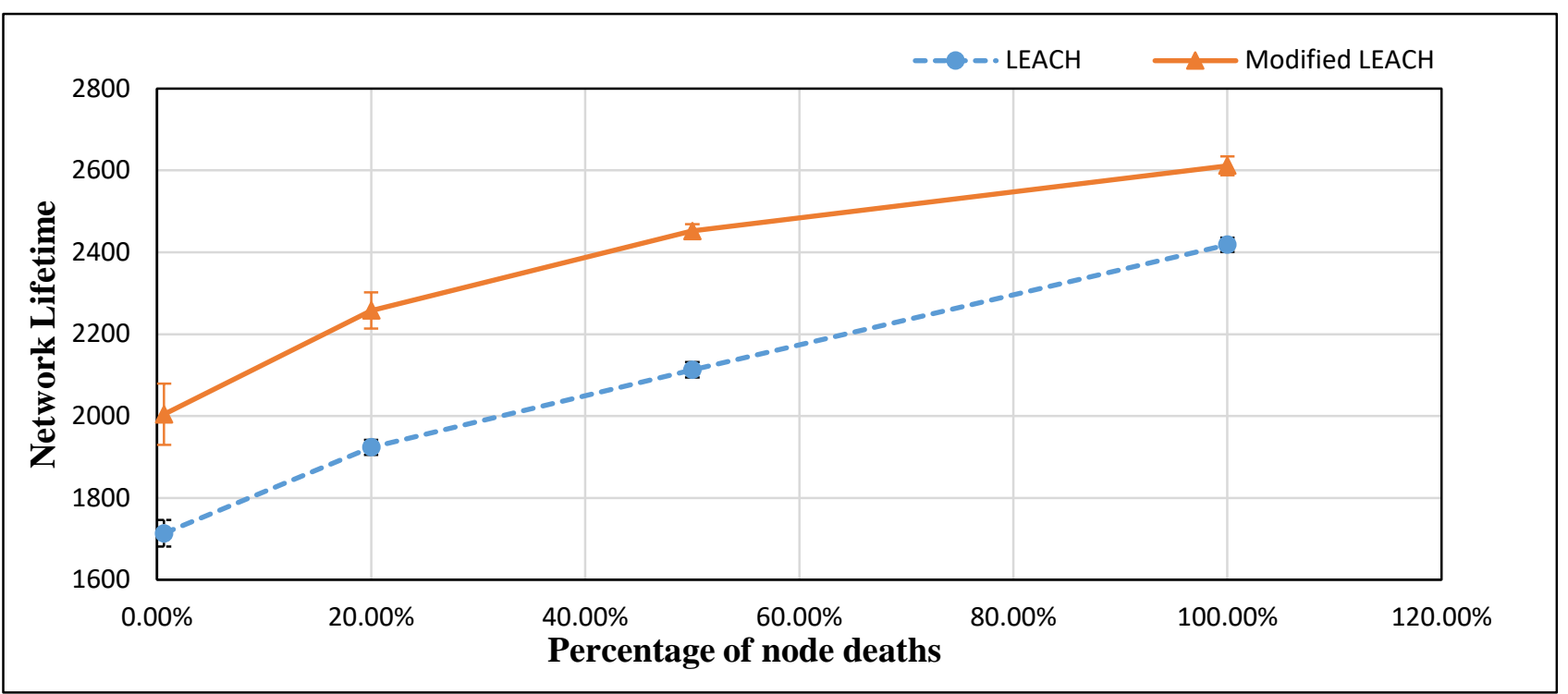

Figure 4.11: Performance results of LEACH and modified LEACH of 150 nodes in $50 \mathrm{~m} \times 50 \mathrm{~m}$ network size with initial energy $=1 \mathrm{~J} /$ node, $\mathrm{p}=0.05$ (i)

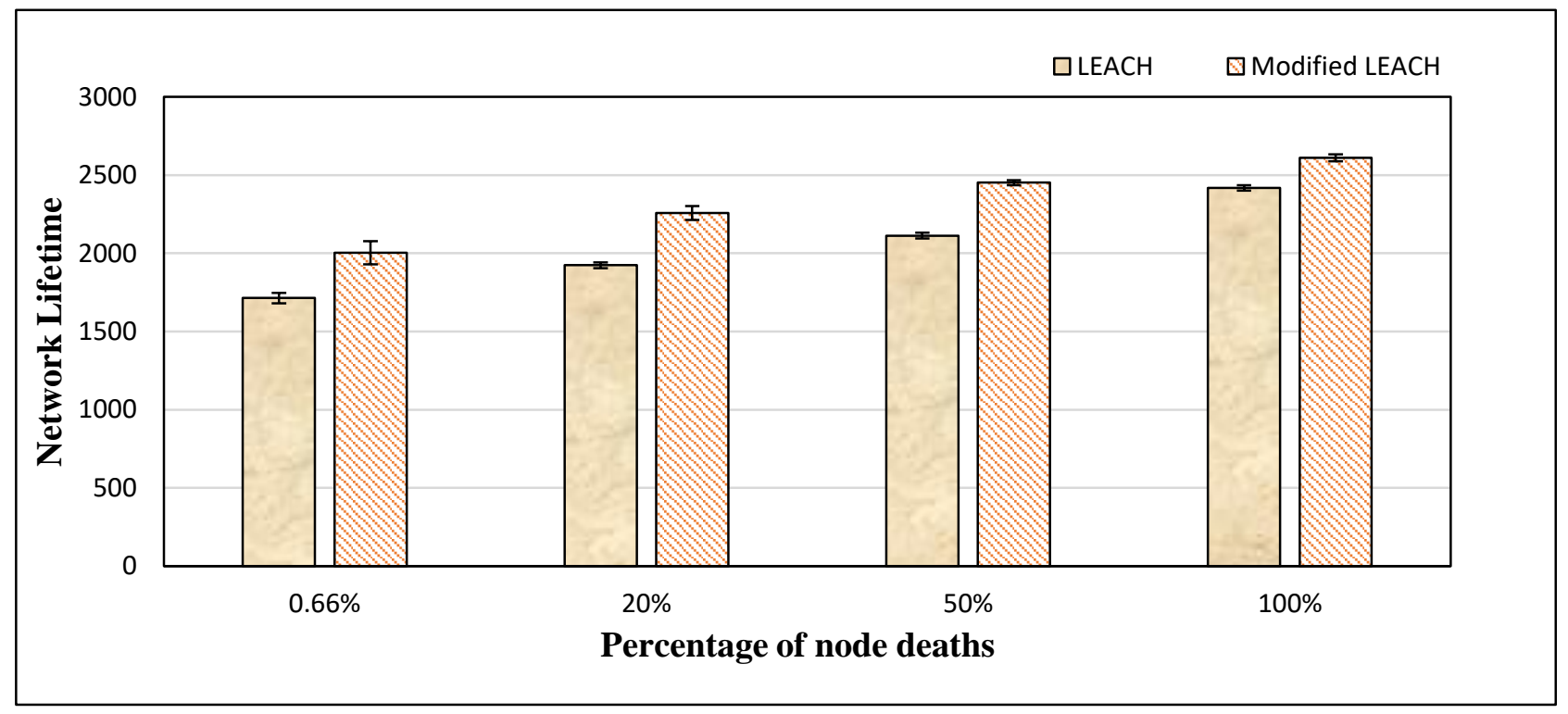

Figure 4.12: Performance results of LEACH and modified LEACH of 150 nodes in $50 \mathrm{~m} \times 50 \mathrm{~m}$ network size with initial energy $=1 \mathrm{~J} /$ node (ii) 
Table 4.5: Network lifetime of LEACH and modified LEACH of 150 nodes in $50 \mathrm{~m} \times 50 \mathrm{~m}$ network size, with initial energy $=1 \mathrm{~J} /$ node

\begin{tabular}{|l|l|l|l|l|l|}
\hline Protocol & $\begin{array}{l}0.66 \% \text { of node } \\
\text { deaths }\end{array}$ & $\begin{array}{l}20 \% \text { of node } \\
\text { deaths }\end{array}$ & $\begin{array}{l}50 \% \text { of node } \\
\text { deaths }\end{array}$ & $100 \%$ of node deaths \\
\hline LEACH & 1713.6 & 1923.6 & 2112.8 & 2418.5 \\
\hline $\begin{array}{l}\text { Modified } \\
\text { LEACH }\end{array}$ & 2004.1 & 2257.7 & 2451.8 & 2611.2 \\
\hline
\end{tabular}

The above results are plotted taking an average of 10 simulations that were performed.

Average stability period of LEACH protocol $=1713.6$ rounds

Average stability period of Modified LEACH protocol $=2004.1$ rounds

Average network lifetime of LEACH protocol $=2418.5$ rounds

Average network lifetime of Modified LEACH protocol $=2611.2$ rounds

In a network of 150 nodes, $0.66 \%$ of node deaths indicate the first node death (FND) i.e. first node death in the network is noted down and plotted on the graph. In this $50 \mathrm{~m} \times 50 \mathrm{~m}$ network, of 150 nodes, modified LEACH protocol is able to improve the stability period as well as the overall lifetime of the network, when compared to basic LEACH protocol. 


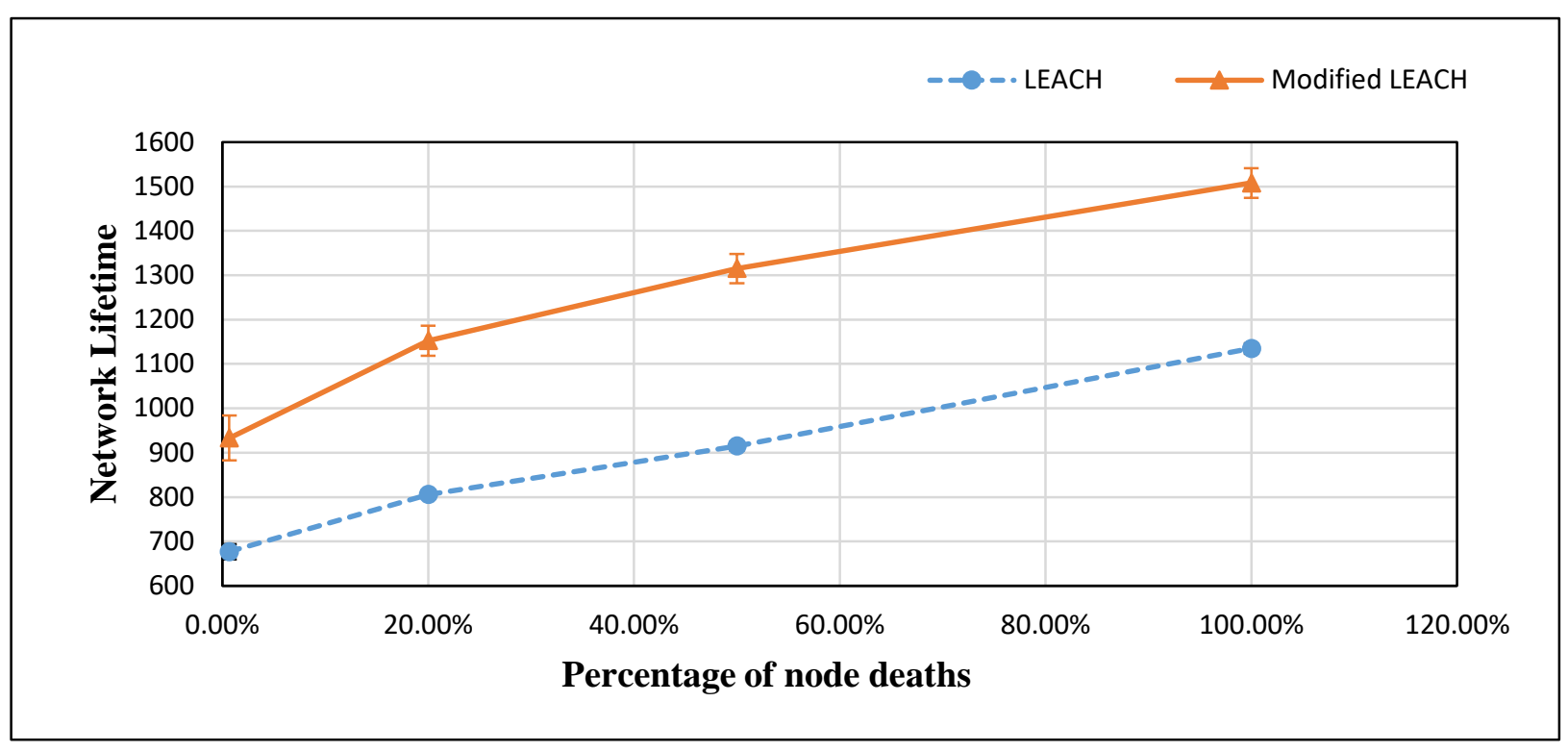

Figure 4.13: Performance results of LEACH and modified LEACH of 150 nodes in $100 \mathrm{~m} \times 100 \mathrm{~m}$ network size with initial energy $=1 \mathrm{~J} /$ node, $\mathrm{p}=0.05$ (i)

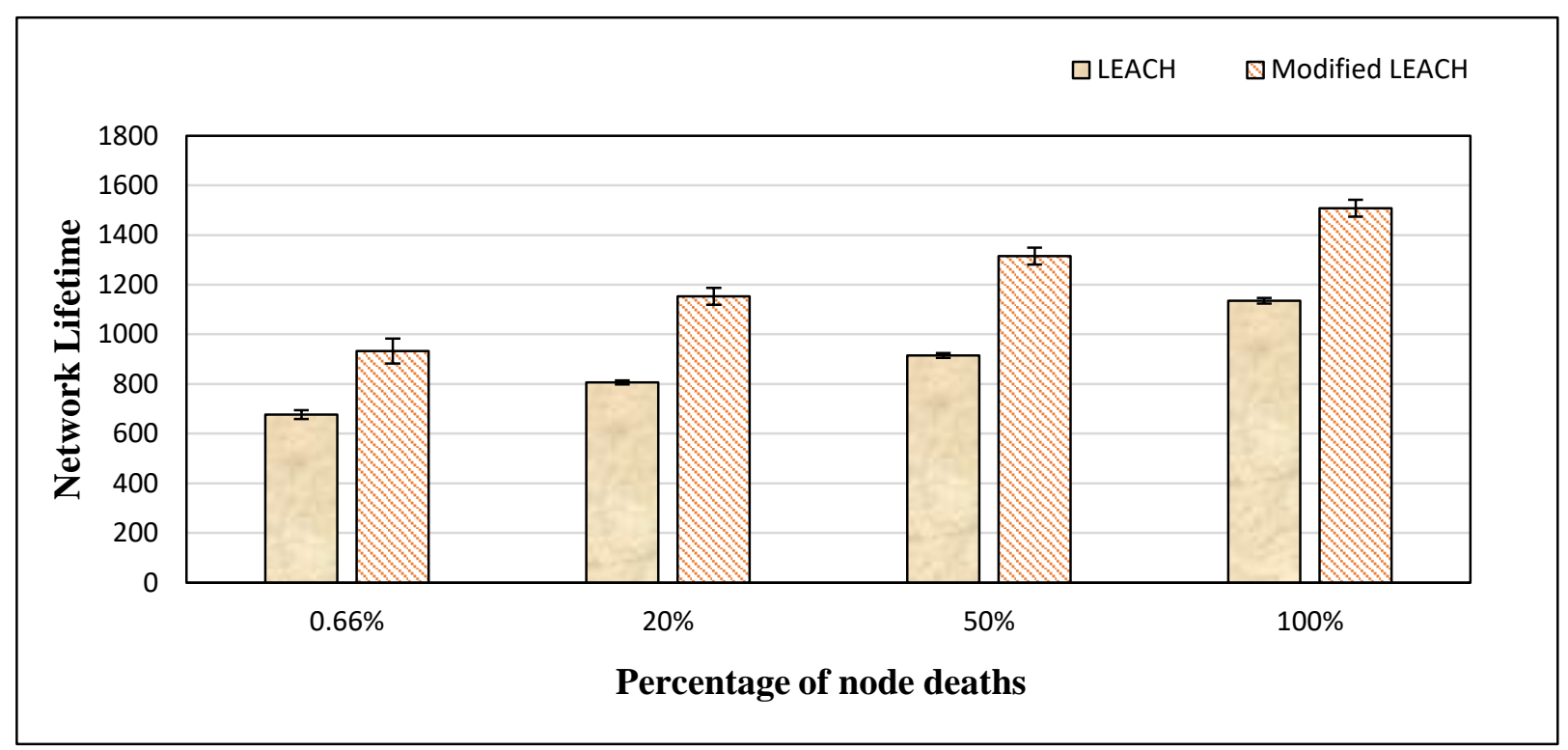

Figure 4.14: Performance results of LEACH and modified LEACH of 150 nodes in $100 \mathrm{~m} \times 100 \mathrm{~m}$ network size with initial energy $=1 \mathrm{~J} /$ node, $\mathrm{p}=0.05$ (ii) 
Table 4.6: Network lifetime of LEACH and modified LEACH of 150 nodes in $100 \mathrm{~m} \times 100 \mathrm{~m}$ network size, with initial energy $=1 \mathrm{~J} /$ node

\begin{tabular}{|l|l|l|l|l|l|}
\hline Protocol & $\begin{array}{l}0.66 \% \text { of node } \\
\text { deaths }\end{array}$ & $\begin{array}{l}20 \% \text { of node } \\
\text { deaths }\end{array}$ & $\begin{array}{l}50 \% \text { of node } \\
\text { deaths }\end{array}$ & $100 \%$ of node deaths \\
\hline LEACH & 676.8 & 805.6 & 914.8 & 1134.8 \\
\hline $\begin{array}{l}\text { Modified } \\
\text { LEACH }\end{array}$ & 933 & 1152.4 & 1315 & 1507.9 \\
\hline
\end{tabular}

The above results are plotted taking an average of 10 simulations that were performed.

Average stability period of $\mathrm{LEACH}$ protocol $=676.8$ rounds

Average stability period of Modified LEACH protocol $=933$ rounds

Average network lifetime of LEACH protocol $=1134.8$ rounds

Average network lifetime of Modified LEACH protocol $=1507.9$ rounds

In a network of 150 nodes, $0.66 \%$ of node deaths indicate the first node death (FND) i.e. first node death in the network is noted down and plotted on the graph. In this $100 \mathrm{~m} \times 100 \mathrm{~m}$ network, of 150 nodes, modified LEACH protocol is able to improve the stability period as well as the overall lifetime of the network. 


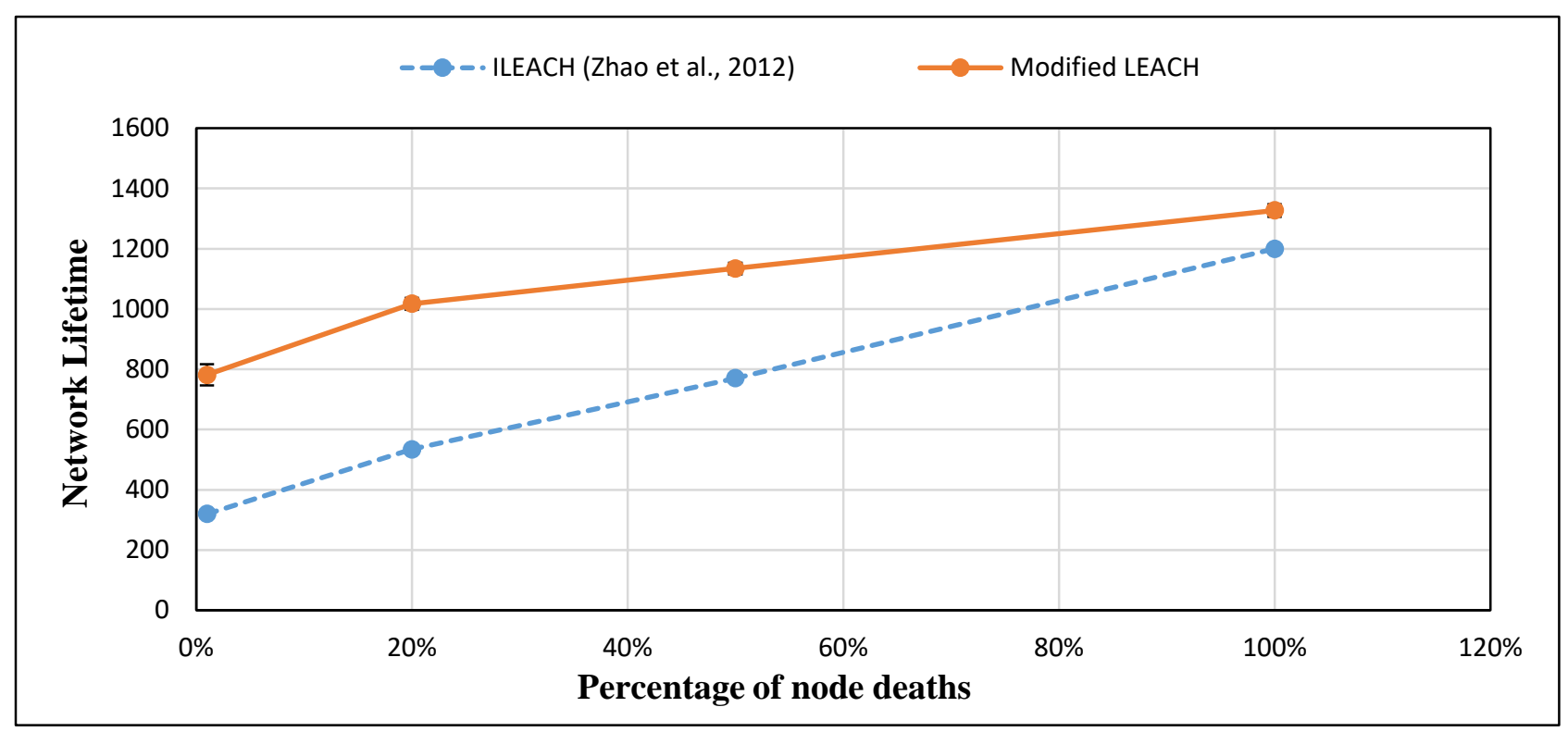

Figure 4.15: Performance results of ILEACH (Zhao et al., 2012) and modified LEACH of 100 nodes in $100 \mathrm{~m} \times 100 \mathrm{~m}$ network size with initial energy $=0.03 \mathrm{~J} /$ node, scenario 2 , $\mathrm{p}=0.05$ (i)

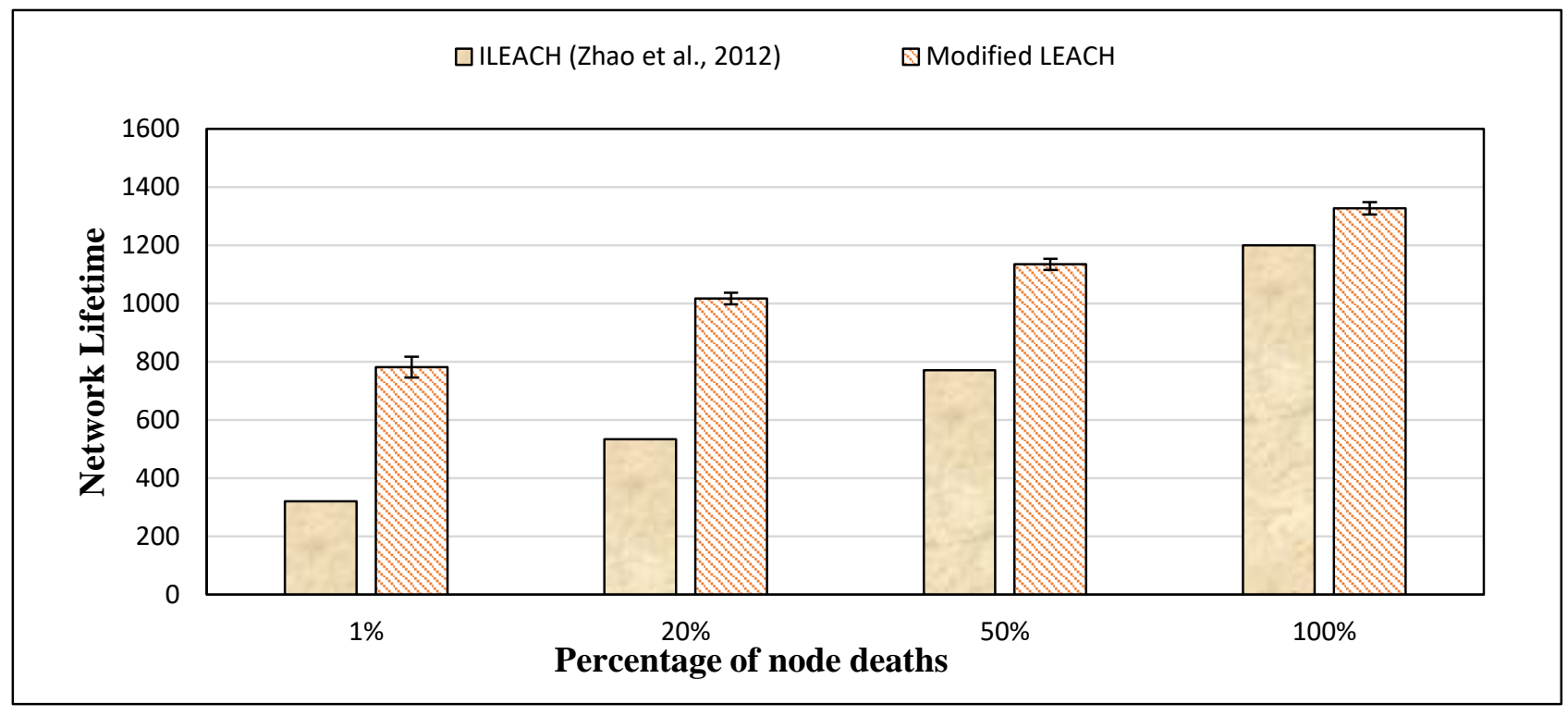

Figure 4.16: Performance results of ILEACH (Zhao et al., 2012) and modified LEACH of 100 nodes in $100 \mathrm{~m} \times 100 \mathrm{~m}$ network size with initial energy $=0.03 \mathrm{~J} /$ node, scenario 2 ,

$$
\mathrm{p}=0.05 \text { (ii) }
$$


Table 4.7: Network lifetime of ILEACH (Zhao et al., 2012) and modified LEACH of 100 nodes in $100 \mathrm{~m} \times 100 \mathrm{~m}$ network size, with initial energy $=0.03 \mathrm{~J} /$ node, scenario 2

\begin{tabular}{|l|l|l|l|l|}
\hline Protocol & $\begin{array}{l}1 \% \text { of node } \\
\text { deaths }\end{array}$ & $\begin{array}{l}20 \% \text { of node } \\
\text { deaths }\end{array}$ & $50 \%$ of node deaths & $100 \%$ of node deaths \\
\hline $\begin{array}{l}\text { ILEACH } \\
\text { (Zhao et al., } \\
\text { 2012) }\end{array}$ & 320 & 534 & 770 & 1200 \\
\hline $\begin{array}{l}\text { Modified } \\
\text { LEACH }\end{array}$ & 781.1 & 1017.2 & 1134.4 & 1327 \\
\hline
\end{tabular}

The above results are plotted taking an average of 10 simulations that were performed. Average stability period of ILEACH (Zhao et al., 2012) protocol $=320$ rounds Average stability period of Modified LEACH protocol $=781.1$ rounds

Average network lifetime of LEACH (Zhao et al., 2012) protocol = 1200 rounds Average network lifetime of Modified LEACH protocol $=1327$ rounds

In a network of 100 nodes, $1 \%$ of node deaths indicate the first node death (FND) in the network. In this $100 \mathrm{~m} \times 100 \mathrm{~m}$ network, of 100 nodes, modified LEACH protocol is able to improve the stability period as well as the overall lifetime of the network. 


\subsection{Analysis on the Simulation Results}

All the above results, depicts clearly, the first node death of the modified LEACH protocol is higher than LEACH protocol and ILEACH (Zhao et al., 2012). This means, the stability period of the network is improved.

Some applications require higher stability period, than the overall lifetime of the network. For such applications of smaller network size, modified LEACH protocol can be used.

For a network size of 50,100 and 150 nodes in both $50 \mathrm{~m} \times 50 \mathrm{~m}$ and $100 \mathrm{~m} \times 100 \mathrm{~m}$, both stability period as well as overall lifetime of the network is improved with the modified LEACH protocol.

At the same time, in all the above scenarios when it is tested with different energies, not only the first node death but the overall lifetime is also improved when compared to the original leach protocol for 50, 100 and 150 nodes and also with ILEACH (Zhao et al., 2012) for 100 nodes. It is because of the modification in $\mathrm{CH}$ selection.

LEACH protocol has a lot of randomness in the process of $\mathrm{CH}$ selection for each round. So, in every round, after the selection of the $\mathrm{CHs}$, the normal sensor nodes suffer from heavy energy consumption, to transmit the packets of information to their respective $\mathrm{CHs}$ which are far away from their vicinity.

In this research, the problem of uneven distribution of $\mathrm{CHs}$ is solved to some major extent by choosing one node as $\mathrm{CH}$ from each sub-region and count of $\mathrm{CHs}$ for every round depends upon the death of last dead node in each sub-region.

In the modified protocol, by the proposed approach of dividing the senor network into equal sub-regions in the beginning itself, makes sure that, all CHs are spread throughout network, that makes the non- $\mathrm{CH}$ nodes, will always have a $\mathrm{CH}$ in their vicinity for every round. This modification has a greater impact on reducing the energy consumption to a lot extent, when compared to the existing basic LEACH protocol.

This preserves the unnecessary energy consumption, that happens when the cluster head is far from their vicinity. This preserved energy will be useful in the increased lifetime of the network. This depicts, impact in uneven distribution of $\mathrm{CHs}$, is quite high. This results in higher usage of energy in network.

Results are plotted depending upon deaths of sensors taken in percentage, happened in system. Lifetime of the network depends upon the number of alive nodes in the network. The lesser the number of node deaths in the network, the more will be the system lifetime. 


\section{CHAPTER 5 \\ CONCLUSION \& FUTURE RECOMMENDATIONS}

\subsection{Conclusion}

LEACH protocol have many drawbacks. One among them is the huge randomness in the selection process of cluster head during its setup phase. Spreading of CHs, in a non-uniform manner makes the system, less energy efficient, less stable.

This problem has been addressed in this research by some extent, in the form of spreading $\mathrm{CHs}$, entirely on the region, by dividing sensor network into equal-sub regions before the starting of setup phase itself. This makes sure that, all the $\mathrm{CHs}$ are spread uniformly, despite number of nodes in their vicinity. By this way, there is $\mathrm{CH}$ for all sensors in their proximity, for every round.

This modification reduces the energy consumption in system, that helps to improve the lifetime of system. This improved protocol has better lifespan in terms of FND, as well as HND, also overall lifetime of the network.

Time period till first node death technically defined as stability period in WSN. Here, improved protocol has better stability period than existing basic LEACH protocol and ILEACH (Zhao et al., 2012) protocol.

Requirement of LEACH protocol varies from application to application. Some applications require higher overall lifetime of the network to collect the data. Some applications require first node death to be in a longer period, since loss of one sensor data can lead to huge loss for their purpose.

A rapid increase in the usage of wireless sensors in different fields like medical, military, traffic, environmental monitoring, automobiles, mobile phones, industries has pushed for a greater demand in the supply and increased research in the field of these protocols.

\subsection{Future Recommendations}

LEACH protocol can be improved in several factors. In this research, that all sensors are spread in a random fashion as well as static including sink. All the sensor nodes are considered as homogenous nodes. But in the practical scenario, it might be different. Some nodes may have greater initial energy than others. So, research should be done, considering some advanced nodes also in the simulation.

Security is one another aspect, which should be taken care of. Since nodes are deployed in a remote location. There is a chance that, a sensor node can be attacked through virtual networks and wrong information can be placed. This leads to a massive failure, when it comes to sensitive applications like military and hospitals. Apart this, there are factors like number of nodes in their vicinity, residual energy of sensors, that to be taken for consideration, for $\mathrm{CH}$ selection, to have a much improved and efficient protocol. 


\section{REFERENCES}

Lindsey, S., \& Raghavendra, C. S. (2002). PEGASIS: Power-efficient gathering in sensor information systems. In Aerospace conference proceedings, 2002. IEEE (Vol. 3, pp. 3-3). IEEE.

Heinzelman, W. R., Chandrakasan, A., \& Balakrishnan, H. (2000, January). Energy-efficient communication protocol for wireless microsensor networks. In System sciences, 2000. Proceedings of the 33rd annual Hawaii international conference on (pp. 10-pp). IEEE

Heinzelman, W. B., Chandrakasan, A. P., \& Balakrishnan, H. (2002). An applicationspecific protocol architecture for wireless microsensor networks. IEEE Transactions on wireless communications, 1(4), 660-670.

Zhao, H., Zhou, W., \& Gao, Y. (2012, November). Energy efficient and cluster based routing protocol for wsn. In 2012 Eighth International Conference on Computational Intelligence and Security (pp. 107-111). IEEE

Elshrkawey, M., Elsherif, S. M., \& Wahed, M. E. (2018). An enhancement approach for reducing the energy consumption in wireless sensor networks. Journal of King Saud University-Computer and Information Sciences, 30(2), 259-267.

Ok, C. S., Lee, S., Mitra, P., \& Kumara, S. (2009). Distributed energy balanced routing for wireless sensor networks. Computers \& Industrial Engineering, 57(1), 125-135.

Yousaf, S., Javaid, N., Qasim, U., Alrajeh, N.A., Khan, Z.A., \& Ahmed, M. (2016). Towards Reliable and Energy-Efficient Incremental Cooperative Communication for Wireless Body Area Networks. Sensors.

Batra, P. K., \& Kant, K. (2016). LEACH-MAC: a new cluster head selection algorithm for Wireless Sensor Networks. Wireless Networks, 22(1), 49-60.

Junping, H., Yuhui, J., \& Liang, D. (2008, July). A time-based cluster-head selection algorithm for LEACH. In Computers and Communications, 2008. ISCC 2008. IEEE Symposium on (pp. 1172-1176). IEEE.

Gui, T., Ma, C., Wang, F., Li, J., \& Wilkins, D. E. (2016, October). A novel cluster-based routing protocol wireless sensor networks using spider monkey optimization. In Industrial Electronics Society, IECON 2016-42nd Annual Conference of the IEEE (pp. 5657-5662). IEEE.

Long, J. Z., Chen, Y. T., Deng, D. M., Li, B., \& Li, F. (2011). Assistant cluster head clustering algorithm based on LEACH protocol. Computer Engineering, 37(7), 103-105.

Ren, P., Qian, J., Li, L., Zhao, Z., \& Li, X. (2010, December). Unequal clustering scheme based leach for wireless sensor networks. In Genetic and Evolutionary Computing (ICGEC), 2010 Fourth International Conference on (pp. 90-93). IEEE. 
Al-Ma'aqbeh, F., Banimelhem, O., Taqieddin, E., Awad, F., \& Mowafi, M. (2012, April). Fuzzy logic based energy efficient adaptive clustering protocol. In Proceedings of the $3 \mathrm{rd}$ International Conference on Information and Communication Systems (p. 21). ACM.

Mahmood, D., Javaid, N., Mahmood, S., Qureshi, S., Memon, A. M., \& Zaman, T. (2013, October). MODLEACH: a variant of LEACH for WSNs. In Broadband and Wireless Computing, Communication and Applications (BWCCA), 2013 Eighth International Conference on (pp. 158-163). IEEE.

Katiyar, V., Chand, N., Gautam, G. C., \& Kumar, A. (2011, March). Improvement in LEACH protocol for large-scale wireless sensor networks. In Emerging Trends in Electrical and Computer Technology (ICETECT), 2011 International Conference on (pp. 1070-1075). IEEE.

Xu, J., Jin, N., Lou, X., Peng, T., Zhou, Q., \& Chen, Y. (2012, May). Improvement of LEACH protocol for WSN. In Fuzzy Systems and Knowledge Discovery (FSKD), 2012 9th International Conference on (pp. 2174-2177). IEEE.

Salim, A., Osamy, W., \& Khedr, A. M. (2014). IBLEACH: intra-balanced LEACH protocol for wireless sensor networks. Wireless networks, 20(6), 1515-1525.

Chen, H., Zhang, C., Zong, X., \& Wang, C. (2013). LEACH-G: an Optimal Cluster-heads Selection Algorithm based on LEACH. JSW, 8(10), 2660-2667.

Bsoul, M., Al-Khasawneh, A., Abdallah, A. E., Abdallah, E. E., \& Obeidat, I. (2013). An energy-efficient threshold-based clustering protocol for wireless sensor networks. Wireless personal communications, 70(1), 99-112. 


\section{APPENDICES}

\section{Appendix 1: System Validation}

LEACH protocol is simulated with the following simulation parameters taken and for validating it, it is compared against the performance results taken from (Lindsey \& Raghavendra, 2002) LEACH.

The performance results are plotted by taking Network lifetime as the parameters. They include $1 \%$ of the node deaths, $20 \%$ of the node deaths, $50 \%$ of the node deaths, $100 \%$ of the node deaths.

Table 7.1 Simulation Parameters

(Lindsey \& Raghavendra, 2002)

\begin{tabular}{|l|l|}
\hline Number of nodes & $\mathrm{N}=100$ \\
\hline Probability of CHs & $\mathrm{P}=0.05$ \\
\hline Network size $(\mathrm{L} \times \mathrm{W})$ & $\begin{array}{l}50 \times 50 \quad \text { square meter ; 100 } \\
\text { meter }\end{array}$ \\
\hline Initial energy of each node & $0.25 \mathrm{~J} / \mathrm{node}, 0.5 \mathrm{~J} /$ node, $1 \mathrm{~J} /$ node \\
\hline Base station location for $50 \times 50$ network size & $(25,150)$ \\
\hline $\begin{array}{l}\text { Base station location for } 100 \times 100 \text { network } \\
\text { size }\end{array}$ & $(50,300)$ \\
\hline Energy model & First order radio energy model \\
\hline Multipath model amplifier & $\epsilon_{a m p}=100 \mathrm{pJ} / \mathrm{bit} / \mathrm{m}^{2}$ \\
\hline Packet size & $2000 \mathrm{bits}$ \\
\hline Energy for data aggregation $E_{D A}$ & $E_{D A}=5 \mathrm{~nJ} / \mathrm{bit}$ \\
\hline Energy for data transmission & $E_{t r}=50 \mathrm{~nJ} / \mathrm{bit}$ \\
\hline Energy for data receiving & $E_{r e}=50 \mathrm{~nJ} / \mathrm{bit}$ \\
\hline Packet transmission rate & $1 \mathrm{packet} / \mathrm{round}$ \\
\hline Deployment type & Random based deployment \\
\hline Number of simulations per one data point & 10 \\
\hline
\end{tabular}

$1 \%$ of node deaths indicate first node death (FND) in the network. $50 \%$ of node deaths indicate half node deaths (HND) in the network. $100 \%$ of node deaths indicate last node death (LND) in the network. 


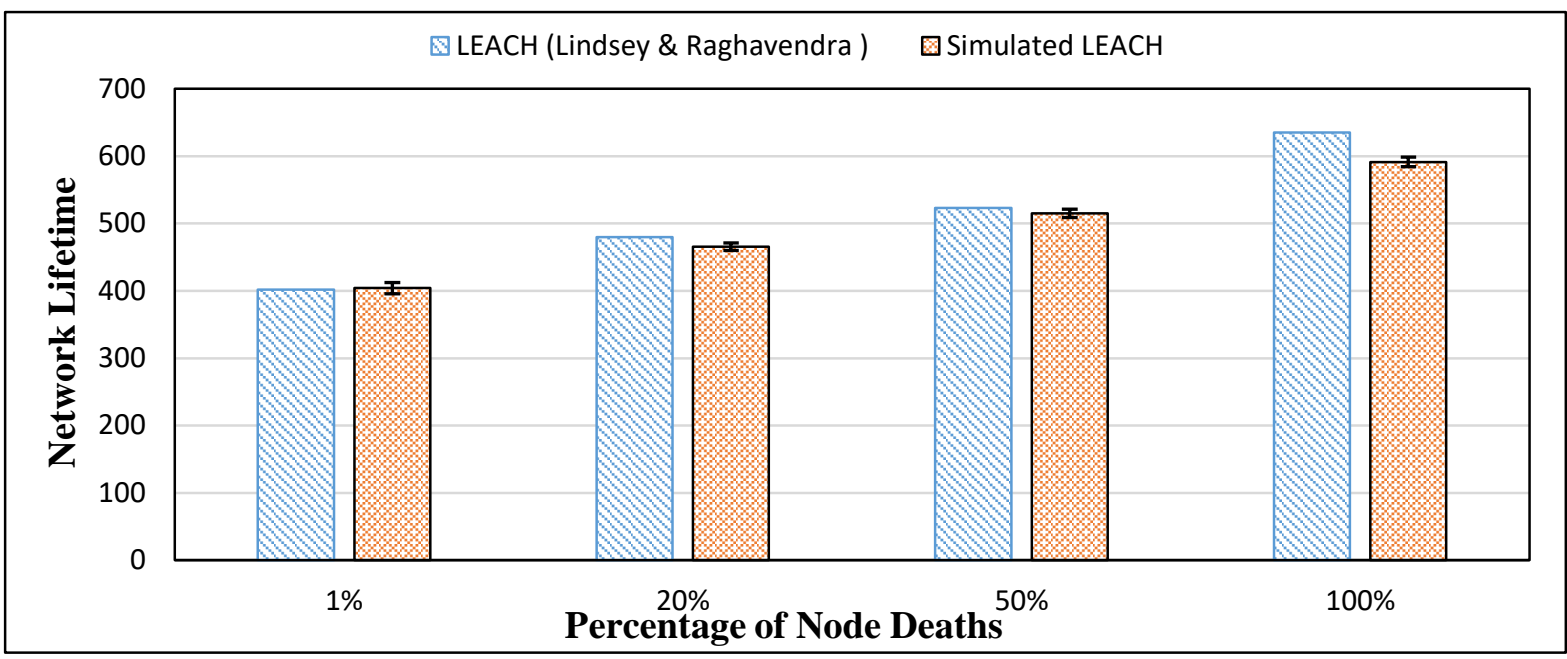

Figure 7.1: Performance results of LEACH (Lindsey \& Raghavendra) and simulated LEACH in $50 \mathrm{~m} \times 50 \mathrm{~m}$ network, initial energy $=0.25 \mathrm{~J} /$ node $(\mathrm{i})$

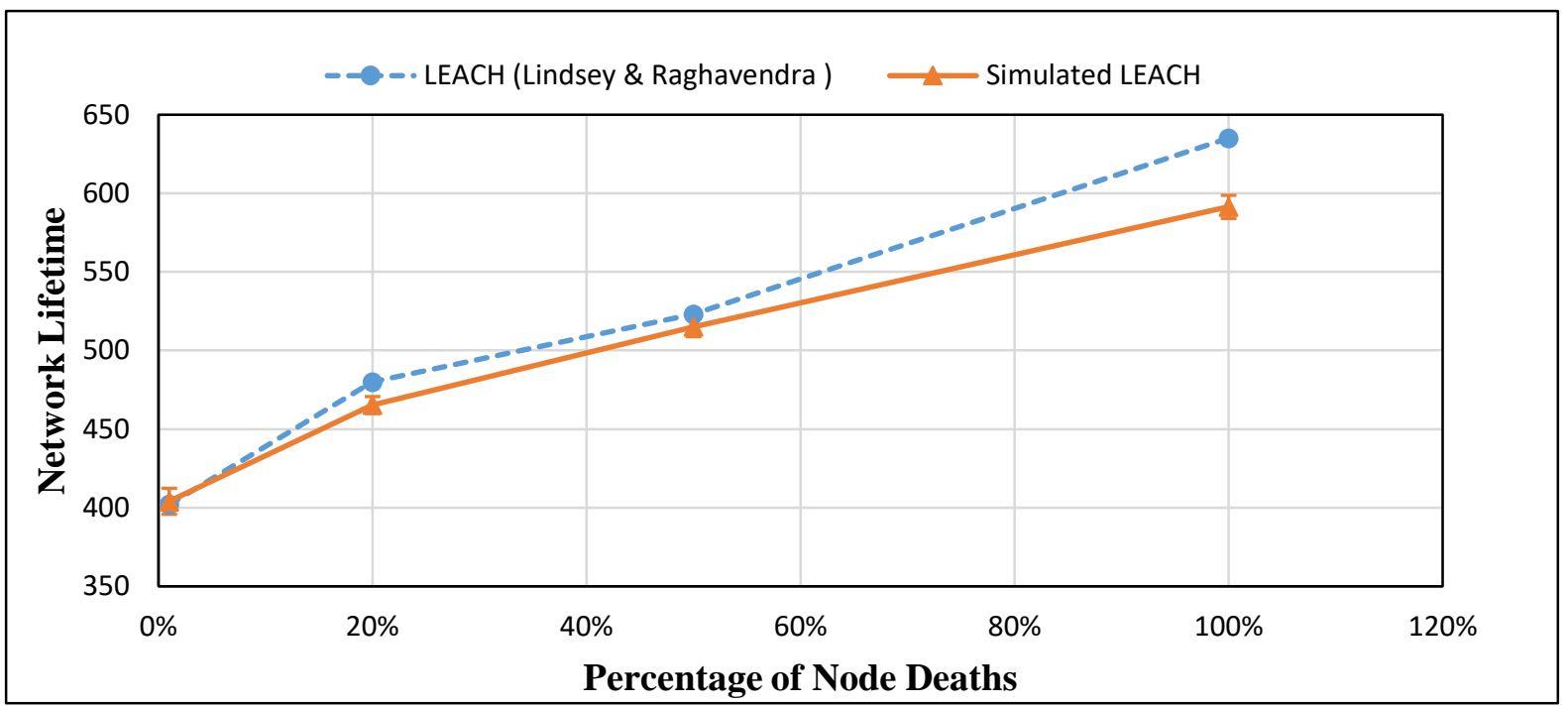

Figure 7.2: Performance results of LEACH (Lindsey \& Raghavendra) and simulated LEACH in $50 \mathrm{~m} \times 50 \mathrm{~m}$ network, initial energy $=0.25 \mathrm{~J} /$ node (ii)

Table 7.1: Network lifetime of LEACH (Lindsey \& Raghavendra) and simulated LEACH in $50 \mathrm{~m} \times 50$ network size, initial energy $=0.25 \mathrm{~J} /$ node

\begin{tabular}{|l|l|l|l|l|}
\hline Protocol & $1 \%$ of node deaths & $20 \%$ of node deaths & $50 \%$ of node deaths & $100 \%$ of node deaths \\
\hline $\begin{array}{l}\text { LEACH (Lindsey } \\
\text { et al., 2002) }\end{array}$ & 402 & 480 & 523 & 635 \\
\hline $\begin{array}{l}\text { Simulated } \\
\text { LEACH }\end{array}$ & 404 & 465.4 & 515.1 & 591.4 \\
\hline
\end{tabular}




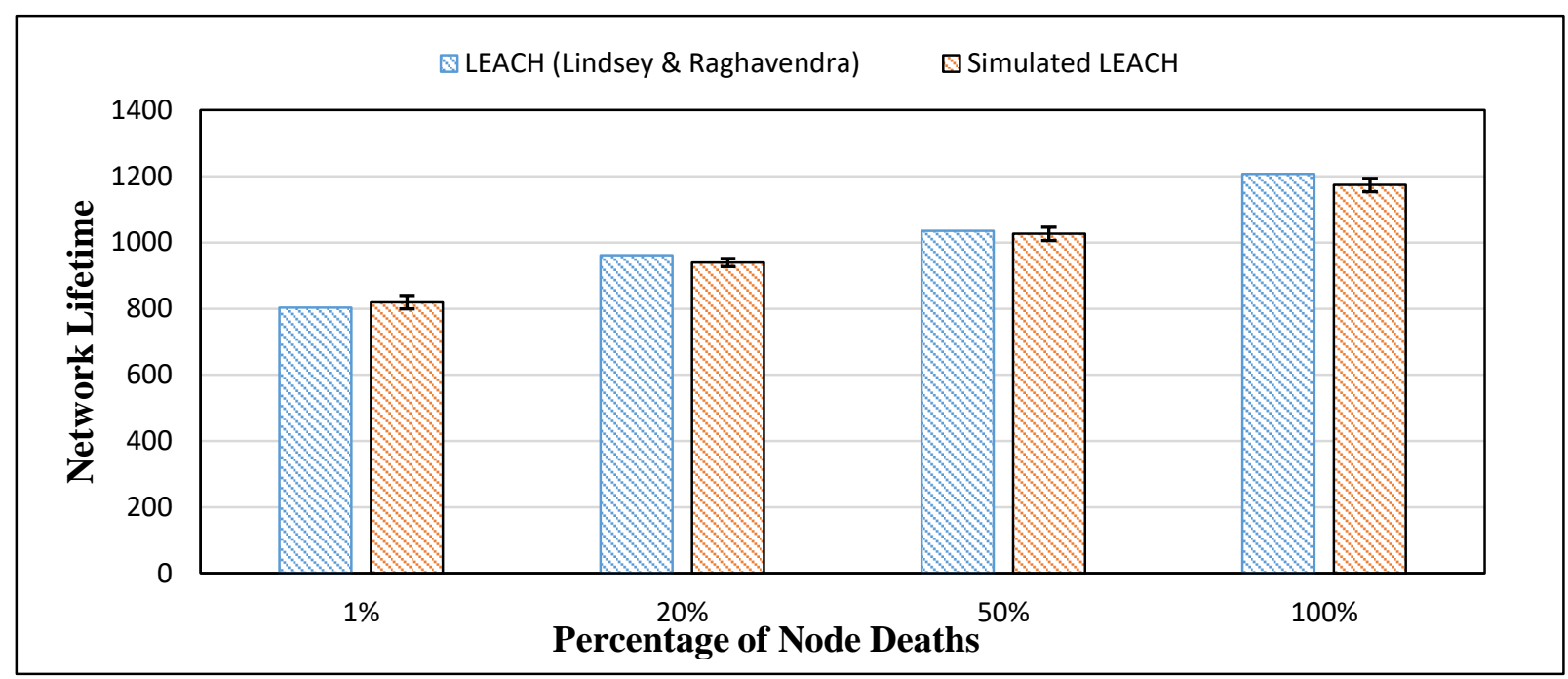

Figure 7.3: Performance results of LEACH (Lindsey \& Raghavendra) and simulated LEACH in $50 \mathrm{~m} \times 50 \mathrm{~m}$ network, initial energy $=0.5 \mathrm{~J} /$ node $(\mathrm{i})$

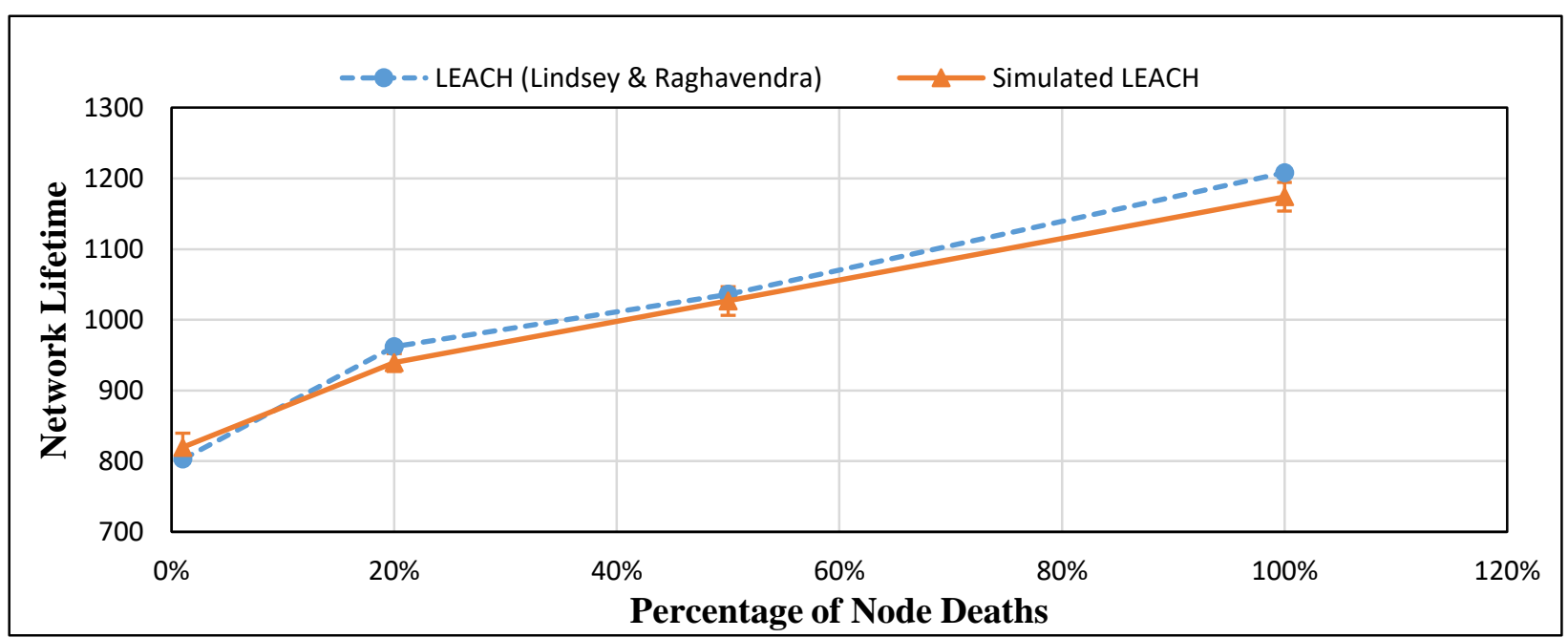

Figure 7.4: Performance results of LEACH (Lindsey \& Raghavendra) and simulated LEACH in $50 \mathrm{~m} \times 50 \mathrm{~m}$ network, initial energy $=0.5 \mathrm{~J} /$ node (ii)

Table 7.2: Network lifetime of LEACH (Lindsey \& Raghavendra) and simulated LEACH in $50 \mathrm{~m} \times 50$ network size, initial energy $=0.5 \mathrm{~J} /$ node

\begin{tabular}{|l|l|l|l|l|}
\hline Protocol & $1 \%$ of node deaths & $20 \%$ of node deaths & $50 \%$ of node deaths & $100 \%$ of node deaths \\
\hline $\begin{array}{l}\text { LEACH (Lindsey } \\
\text { et al., 2002) }\end{array}$ & 803 & 962 & 1036 & 1208 \\
\hline Simulated LEACH & 819.5 & 939.5 & 1026.6 & 1174 \\
\hline
\end{tabular}




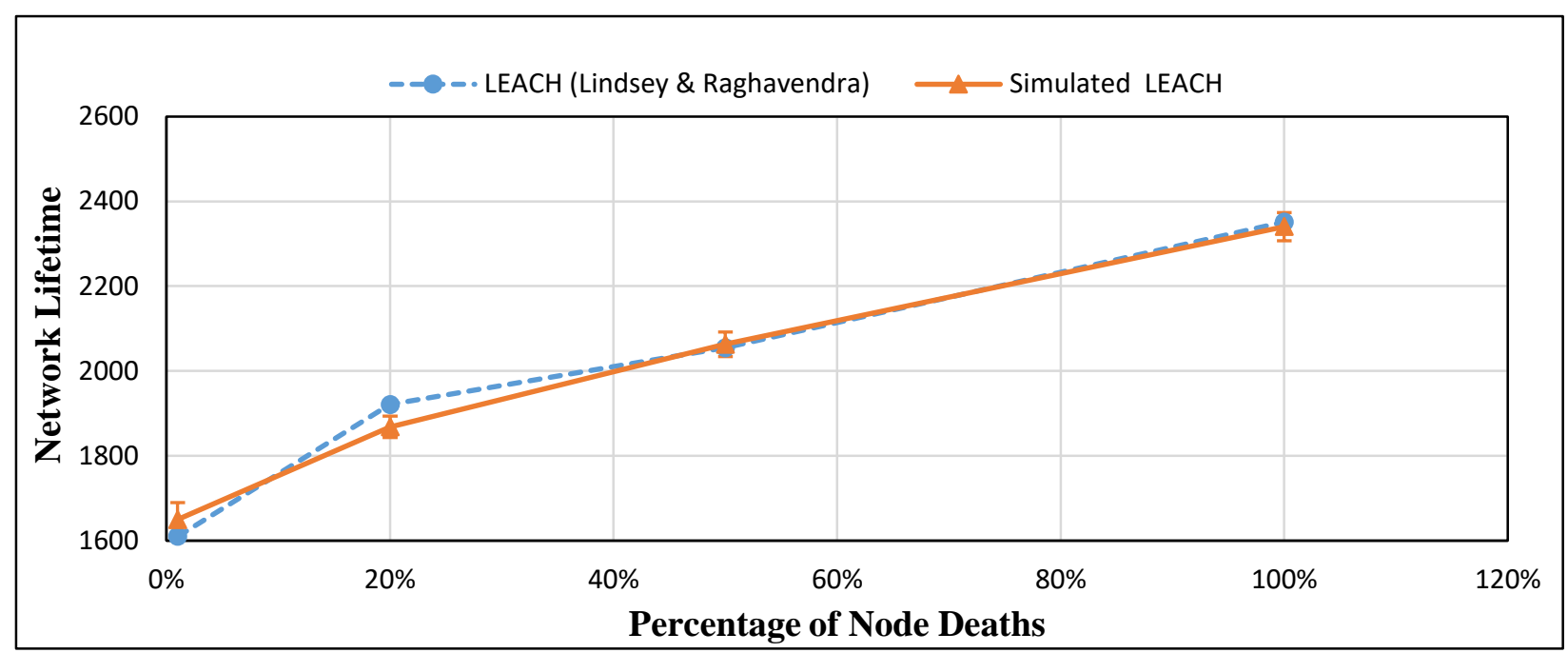

Figure 7.5: Performance results of LEACH (Lindsey \& Raghavendra) and simulated LEACH in $50 \mathrm{~m} \times 50 \mathrm{~m}$ network, initial energy $=1 \mathrm{~J} /$ node $(\mathrm{i})$

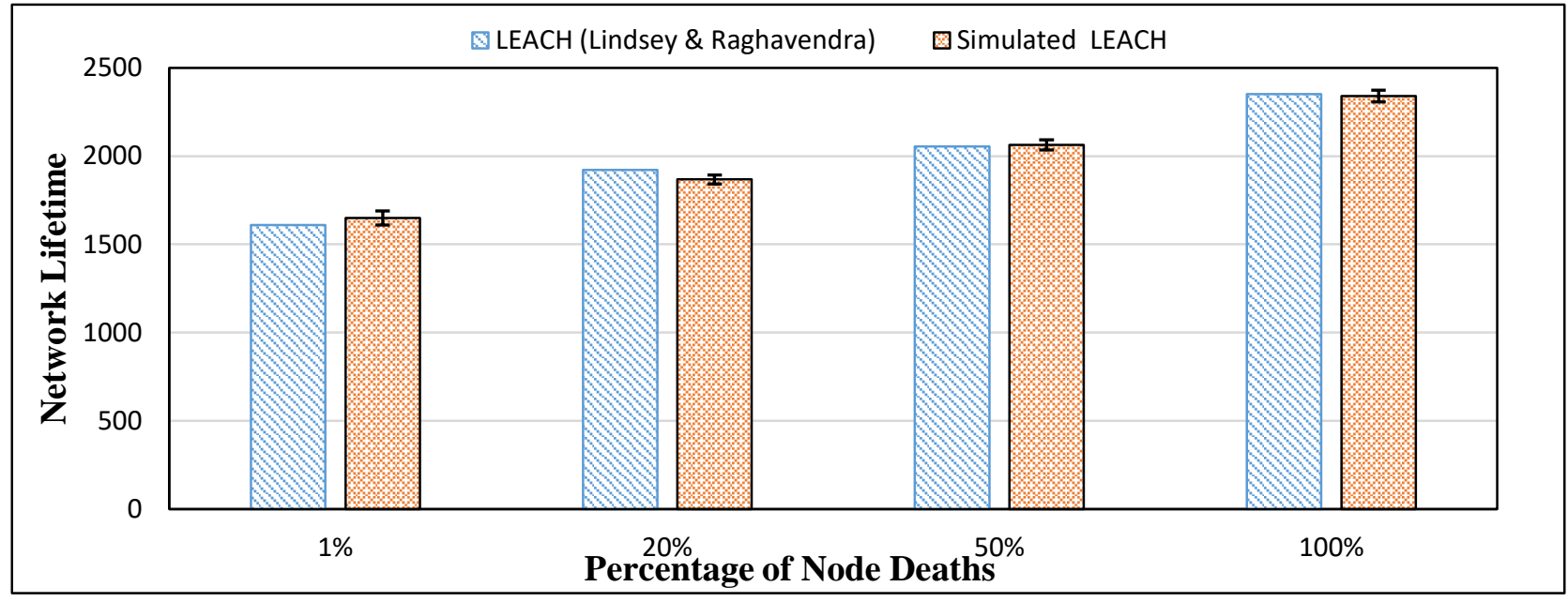

Figure 7.6: Performance results of LEACH (Lindsey \& Raghavendra) and simulated LEACH in $50 \mathrm{~m} \times 50 \mathrm{~m}$ network, initial energy $=1 \mathrm{~J} /$ node (ii)

Table 7.3: Network lifetime of LEACH (Lindsey \& Raghavendra) and simulated LEACH in $50 \mathrm{~m} \times 50$ network size, initial energy $=1 \mathrm{~J} /$ node

\begin{tabular}{|l|l|l|l|l|}
\hline Protocol & $1 \%$ of node deaths & $20 \%$ of node deaths & $50 \%$ of node deaths & $100 \%$ of node deaths \\
\hline $\begin{array}{l}\text { LEACH (Lindsey } \\
\text { et al., 2002) }\end{array}$ & 1610 & 1921 & 2055 & 2351 \\
\hline Simulated LEACH & 1649.9 & 1868.3 & 2063.2 & 2340.5 \\
\hline
\end{tabular}




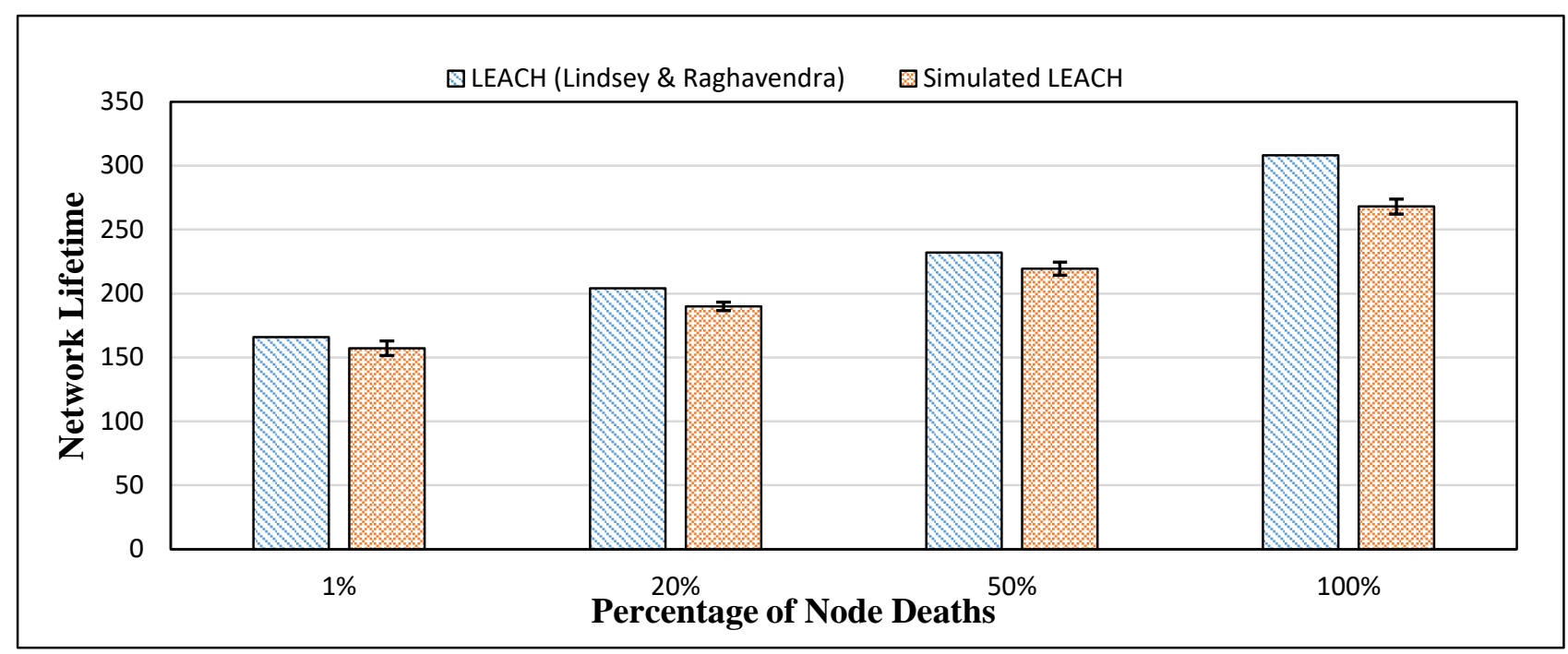

Figure 7.7: Performance results of LEACH (Lindsey \& Raghavendra) and simulated LEACH in $100 \mathrm{~m} \times 100 \mathrm{~m}$ network, initial energy $=0.25 \mathrm{~J} /$ node (i)

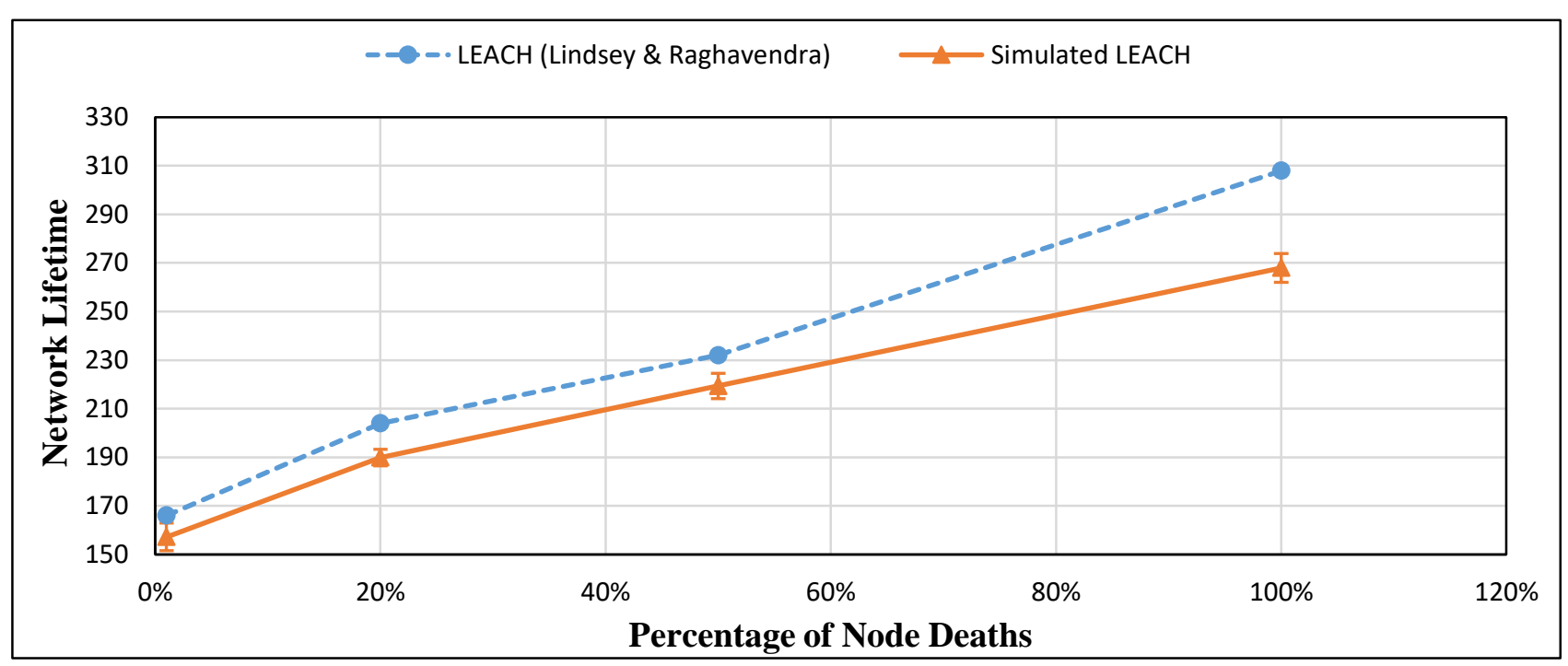

Figure 7.8: Performance results of LEACH (Lindsey \& Raghavendra) and simulated LEACH in $100 \mathrm{~m} \times 100 \mathrm{~m}$ network, initial energy $=0.25 \mathrm{~J} /$ node (ii)

Table 7.5: Network lifetime of LEACH (Lindsey \& Raghavendra) and simulated LEACH in $100 \mathrm{~m} \times 100$ network size, initial energy $=0.25 \mathrm{~J} /$ node

\begin{tabular}{|l|l|l|l|l|}
\hline Protocol & $\begin{array}{l}1 \% \text { of node } \\
\text { deaths }\end{array}$ & $20 \%$ of node deaths & $50 \%$ of node deaths & $100 \%$ of node deaths \\
\hline $\begin{array}{l}\text { LEACH (Lindsey et } \\
\text { al.,2002) }\end{array}$ & 166 & 204 & 232 & 308 \\
\hline Simulated LEACH & 157.2 & 189.9 & 219.4 & 268 \\
\hline
\end{tabular}




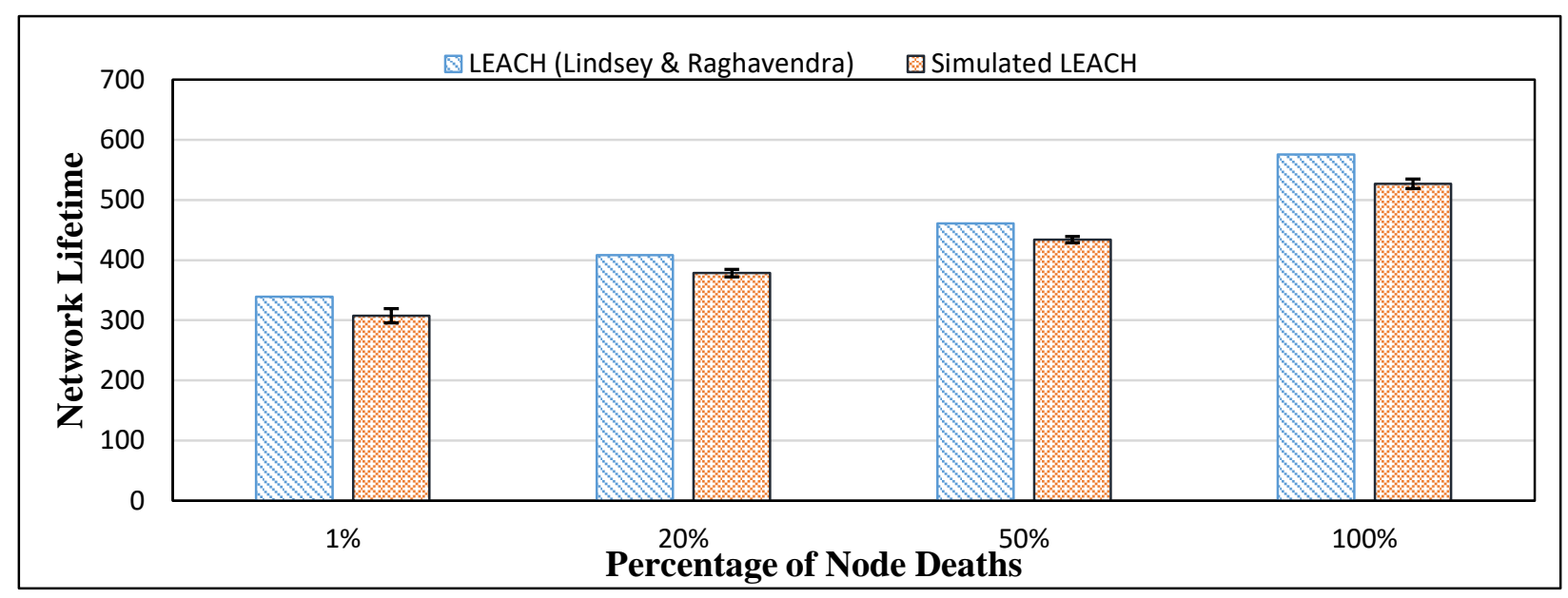

Figure 7.9: Performance results of LEACH (Lindsey \& Raghavendra) and simulated LEACH in $100 \mathrm{~m} \times 100 \mathrm{~m}$ network, initial energy $=0.5 \mathrm{~J} /$ node $(\mathrm{i})$

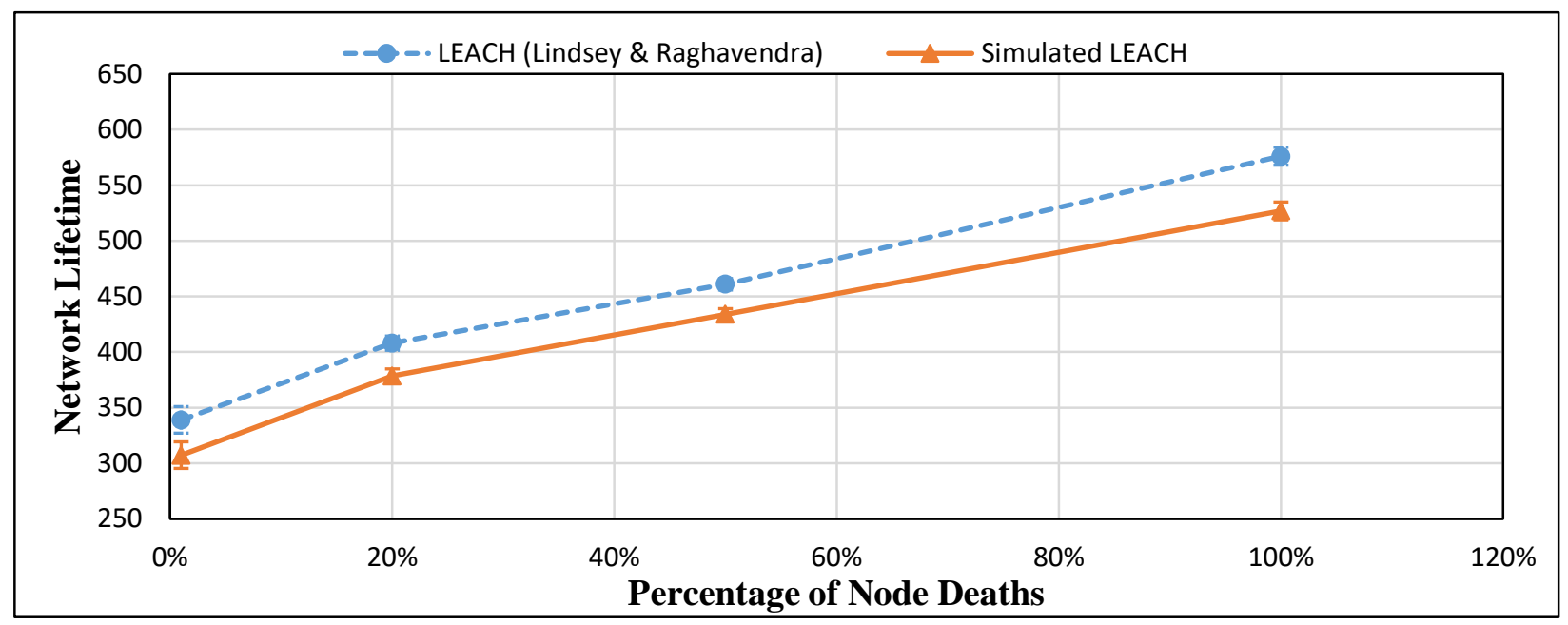

Figure 7.10: Performance results of LEACH (Lindsey \& Raghavendra) and simulated LEACH in $100 \mathrm{~m} \times 100 \mathrm{~m}$ network, initial energy $=0.5 \mathrm{~J} /$ node (ii)

Table 7.5: Network lifetime of LEACH (Lindsey \& Raghavendra) and simulated LEACH in $100 \mathrm{~m} \times 100$ network size, initial energy $=0.5 \mathrm{~J} /$ node

\begin{tabular}{|l|l|l|l|l|}
\hline Protocol & $1 \%$ of node deaths & $20 \%$ of node deaths & $50 \%$ of node deaths & $100 \%$ of node deaths \\
\hline $\begin{array}{l}\text { LEACH (Lindsey } \\
\text { et al., 2002) }\end{array}$ & 339 & 408 & 461 & 576 \\
\hline Simulated LEACH & 307.2 & 378.5 & 434 & 527 \\
\hline
\end{tabular}




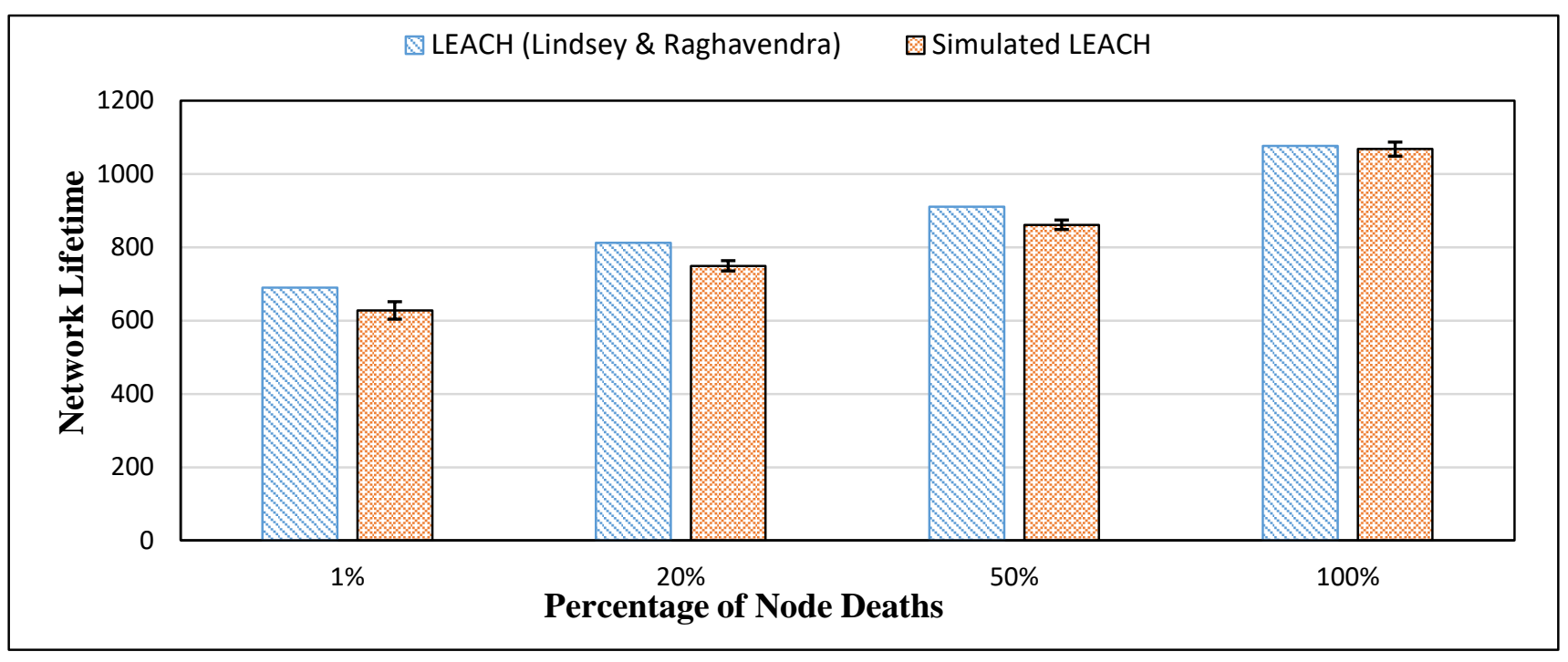

Figure 7.11: Performance results of LEACH (Lindsey \& Raghavendra) and simulated LEACH in $100 \mathrm{~m} \times 100 \mathrm{~m}$ network, initial energy $=1 \mathrm{~J} /$ node (i)

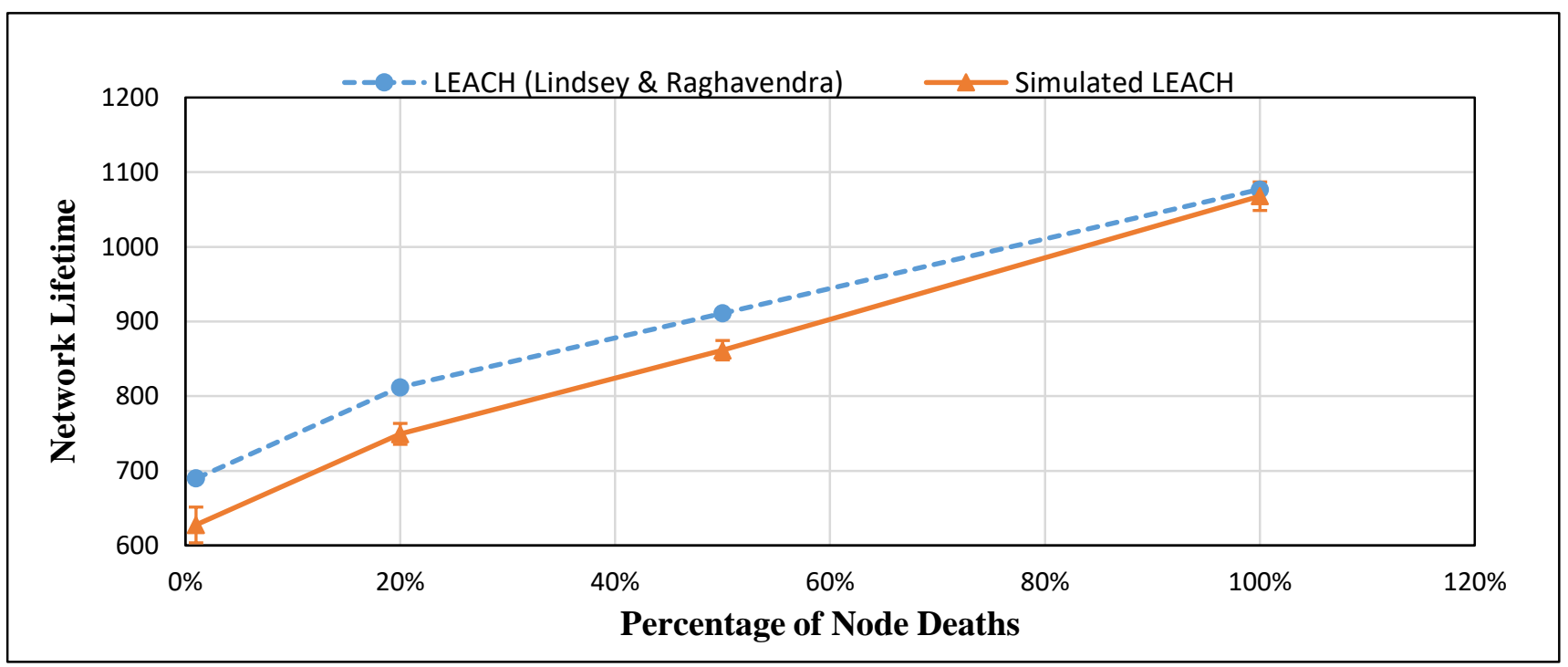

Figure 7.12: Performance results of LEACH (Lindsey \& Raghavendra) and simulated LEACH in $100 \mathrm{~m} \times 100 \mathrm{~m}$ network, initial energy $=1 \mathrm{~J} /$ node (ii)

Table 7.6: Network lifetime of LEACH (Lindsey \& Raghavendra) and simulated LEACH in $100 \mathrm{~m} \times 100$ network size, initial energy $=1 \mathrm{~J} /$ node

\begin{tabular}{|l|l|l|l|l|}
\hline Protocol & $\begin{array}{l}1 \% \text { of node } \\
\text { deaths }\end{array}$ & $\begin{array}{l}20 \% \text { of node } \\
\text { deaths }\end{array}$ & $50 \%$ of node deaths & $100 \%$ of node deaths \\
\hline $\begin{array}{l}\text { LEACH (Lindsey et } \\
\text { al.,2002) }\end{array}$ & 690 & 812 & 911 & 1077 \\
\hline Simulated LEACH & 627.7 & 749.5 & 861.5 & 1068 \\
\hline
\end{tabular}


Simulated LEACH results are plotted taking an average of 10 simulations. It is compared against the results of LEACH (Lindsey \& Raghavendra, 2002). It can be seen that the simulated LEACH protocol gives closer results, by which it justifies the system validation. 